This item was submitted to Loughborough's Research Repository by the author.

Items in Figshare are protected by copyright, with all rights reserved, unless otherwise indicated.

\title{
Properties of water confined in hydroxyapatite nanopores as derived from molecular dynamics simulations
}

PLEASE CITE THE PUBLISHED VERSION

http://dx.doi.org/10.1007/s00214-015-1653-3

\section{PUBLISHER}

(c) Springer-Verlag

\section{VERSION}

AM (Accepted Manuscript)

\section{PUBLISHER STATEMENT}

This work is made available according to the conditions of the Creative Commons Attribution-NonCommercialNoDerivatives 4.0 International (CC BY-NC-ND 4.0) licence. Full details of this licence are available at: https://creativecommons.org/licenses/by-nc-nd/4.0/

\section{LICENCE}

CC BY-NC-ND 4.0

\section{REPOSITORY RECORD}

Pham, Thanh Tung, Thibault Lemaire, Evangeline Capiez-Lernout, Marius Lewerenz, Quy-Dong To, Jamieson K. Christie, Devis Di Tommaso, Nora H. de Leeuw, and Salah Naili. 2015. "Properties of Water Confined in Hydroxyapatite Nanopores as Derived from Molecular Dynamics Simulations". figshare. https://hdl.handle.net/2134/18286. 


\title{
Properties of water confined in hydroxy-apatite nanopores as derived from molecular dynamics simulations
}

\author{
Thanh Tung Pham ${ }^{* a}$ - Thibault Lemaire ${ }^{* a}$ - Evangéline \\ Capiez-Lernout $^{* b}$. Marius Lewerenz ${ }^{* b}$. Quy-Dong To*b . \\ Jamieson K. Christie ${ }^{\ddagger}$. Devis Di Tommaso ${ }^{\dagger}$. Nora H. de \\ Leeuw $^{\ddagger} \cdot$ Salah Naili ${ }^{* a}$
}

Received: date / Accepted: date

\begin{abstract}
Bone tissue is characterised by nanopores inside the collagen-apatite matrix where fluid can exist and flow. The description of the fluid flow within the bone has however mostly relied on a macroscopic continuum mechanical treatment of the system and, for this reason, the role of these nanopores has been largely overlooked. However, neglecting the nanoscopic behaviour of fluid within the bone volume could result in large errors in the overall description of the dynamics of fluid. In this work we have investigated the nanoscopic origin of fluid motion by conducting atomistic molecular dynamics simulations of water confined between two parallel surfaces of hydroxyapatite (HAP), which is the main mineral phase of mammalian bone. The polarizable core-shell interatomic potential model used in this work to simulate the HAP-water system has been extensively assessed with respect to $a b$ initio calculations and experimental data. The structural (pair distribution functions), dynamical (self-diffusion coefficients) and transport (shear viscosity coefficients) properties of confined water have been computed as a function of the size of the nanopore and the temperature of the system. Analysis of the results shows that the dynamical and transport properties of water are significantly affected by the confinement, which is explained in terms of the layering of water on the surface of HAP as a consequence of the molecular interactions between the water molecules and the calcium and phosphate ions at the surface. Using molecular dynamics simulations we

\footnotetext{
* Université Paris-Est, Laboratoire Modélisation et Simulation Multi Echelle, MSME UMR 8208 CNRS

a 94010 Créteil cedex, France. Corresponding author. E-mail: salah.naili@univ-paris-est.fr

$b 77454$ Marne la Vallée cedex 2, France

¥ Department of Chemistry, University College London, 20 Gordon Street, London, UK WC1H 0AJ

$\uparrow$ School of Biological and Chemical Sciences, Queen Mary University of London, Mile End Road, London E1 4NS
} 
have also computed the slip length of water on the surface of HAP, the value of which has never been reported before.

Keywords Water properties $\cdot$ Nanopores $\cdot$ Hydroxyapatite $\cdot$ Bone fluid flow

\section{Introduction}

The main mineral phase of mammalian bone is carbonated hydroxyapatite [1] (HAP), which grows as nanometric platelets on a collagen matrix [2], and for this reason HAP-based materials are of significant importance in the field biomaterials owing to their clinical applications as bone cements [3] or scaffolds in bone tissue engineering [4]. After the mineral and organic phases, water occupies the largest volume fraction in bone, and therefore role of water in calcified tissues has been extensively studied [5,6]. Water molecules within the bones can be classified as "bound" and "free". Water molecules that are directly coordinated to the calcium ions in the bulk of the HAP crystal, or that are strongly adsorbed to the organic phase of the bond represent structural bone water. Free water molecules, on the other hand, occupy the different porosity levels of the bone tissue. The movement of this bulk water is known to contribute to bone activity through the remodelling of signal transmissions. Obtaining insight into bone's ability to transport fluid by quantifying the bone permeability is a challenging topic of contemporary bone biomechanics.

The bone tissue is characterized by three levels of porosity: the vasculature, the lacunar-canalicular network and the nano-size spaces inside the collagen-apatite matrix [7]. However, the role of nanopores on the fluid flow within the bone has been largely overlooked, most likely because the description of fluid flow has been so far restricted to a double-porosity approach involving vasculature (Haversian system) and submicrometer pores of canalicular network $[8,9]$. In the framework of porous media theory, the bone interstitial fluid flow is macroscopically described by a Darcy law obtained by upscaling a description of the flow at the pore scale to the macroscopic scale organ $[10,11]$.

Determining the behaviour of fluids confined in hydroxyapatite nanopores would be of great interest to improve our understanding of bone and bone graft materials. However, methods based on continuum mechanics are not suited when dealing with fluid transport in nanopores where it is crucial to have an atomic-level description of the interactions occurring at the interface between the hydroxyapatite and the fluid. 
In fact, in HAP pores with a size not much larger than few nanometres, surface effects such as hydration, ion-water interactions and steric interactions, may induce changes to the fluid properties, and can therefore play a significant role in transport phenomena at the nanoscale. For instance, the crystalline swelling stage of slowly hydrated clays have been observed experimentally [12] and interactions with the platelet surfaces have been shown to modify diffusion and hydrodynamic flow [13].

Molecular dynamics (MD) simulations based on an atomistic description of the particles of the system are capable of taking into account, for example, surface and hydration effects that otherwise would be inaccessible from a continuum description of the system. Molecular simulation is therefore the method of choice to describe a confined fluid behaviour.

In this paper, we present MD simulations of water confined between two parallel surfaces of hydroxyapatite. Various properties of the confined water, including its structure, self-diffusion coefficients and shear-viscosity, have been computed as a function of the size of the nanopore and the temperature. The simulations reported in this paper present a novel way to simulate hydrodynamics within the bone at the nanoscopic scale. Using these simulations we have also determined hydrodynamic properties of water within the bone at the macroscopic scale, including the dynamic viscosity of confined water and the slip length of water at the HAP surface.

\section{Molecular dynamics simulation}

\subsection{Hydroxyapatite structure}

The hydroxyapatite unit cell can be represented as $\left(\mathrm{Ca}_{10}\left(\mathrm{PO}_{4}\right)_{6}(\mathrm{OH})_{2}\right)$. Its crystal structure is described as an approximate hexagonal close packed set of spheres in which each sphere represents a tetrahedral $\mathrm{PO}_{4}^{3-}$ ion (see Fig. 1). Hydroxyapatite is normally present in the form of thin micro-plates with dimensions $(L \times l \times e)$ in which $L=250-500 \AA, l=150-250 \AA$ and $e \sim 25 \AA[14]$.

The simulation box is described by the Cartesian coordinate system $(x, y, z)$ associated with the orthogonal basis $(\mathbf{x}, \mathbf{y}, \mathbf{z})$ as shown in Fig. 2. This simulation box consists of a parallelepiped cell with a $2 \times 2 \times 3$ slab of hydroxyapatite crystal and a water layer whose height varies from $10 \AA$ to $100 \AA$. The initial density of water is set to its bulk value in standard conditions which is given by $1000 \mathrm{~kg} \cdot \mathrm{m}^{-3}$. Cell parameters and crystallographic data of 

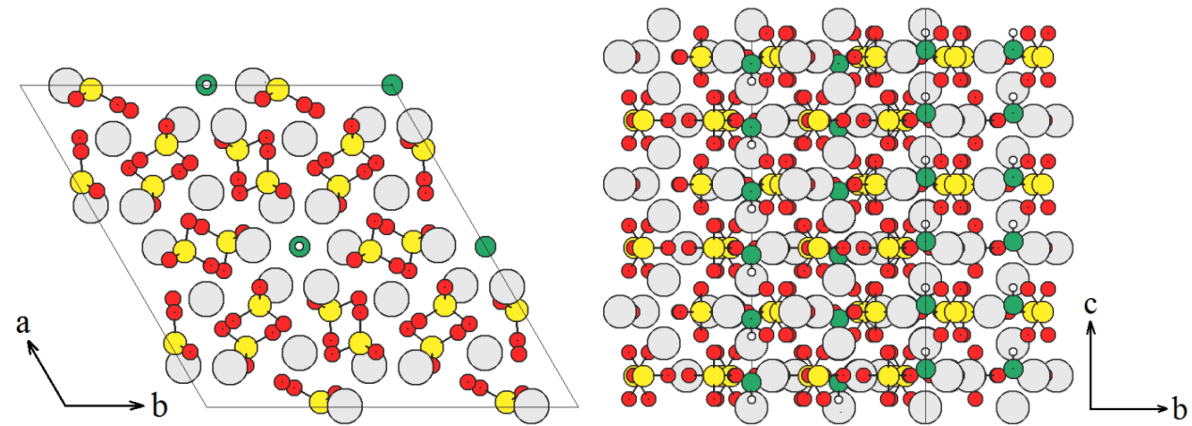

Fig. 1 Plan and side view of the hydroxyapatite (0001) surface $\left(\mathrm{Ca}=\right.$ gray, $\mathrm{P}=$ yellow, $\mathrm{O}_{\text {phosphate }}=$ red, $\mathrm{O}_{\mathrm{OH}}=$ green, $\mathrm{H}=$ white $(\mathrm{see}$ color online).

Sudarsanan and Young [15] are used for the initial configuration of the hydroxyapatite structure $(a=b=9.424 \AA$, $c=6.879 \AA$, space group $P 6_{3} / m$ symmetry).

\subsection{Method and simulation parameters}

The HAP platelets and water layers (whose thickness may vary depending on the confinement degree that is studied) are stacked in a periodic fashion in the $z$-axis (see Fig. 2). Note that the inter-platelet distance, which represents the thickness of the water layer, is more or less controlled by the number of water molecules that are put into the initial simulation box. For instance, the initial box presented in this figure contains 310 water molecules to which corresponds a inter-platelet distance of approximatively $25 \AA$ after equilibration.

The interactions between particles were represented by the interatomic potential model previously developed by de Leeuw $[16,17]$ for HAP and water systems, which includes electronic polarisability via the shell model of Dick and Overhauser (see Tab. 1) [18].

This model describes the polarisable oxygen ions by a shell representing the electronic charge cloud connected to a core by a spring with a rigidity constant $k$. The shells can be treated by two approaches. The first one consists in using massless shells and performing a shell-only energy minimization at each time step. The second one is to assign a small mass to the shells that obey the normal dynamic laws. Here, we adopt this second strategy and introduce a shell mass of $0.2 \mathrm{u}$. This value is small enough compared to the hydrogen atom mass $(1.0 \mathrm{u})$ to avoid energy exchange between the vibrations of oxygen core and shell and oxygen and hydrogen vibrations [16]. The core shell water model is empirically fitted to reproduce the experimental dipole moment, $\mathrm{O}-\mathrm{H}$ bond length and $\mathrm{H}$ - 
Table 1 Potential parameters used in this work [17]

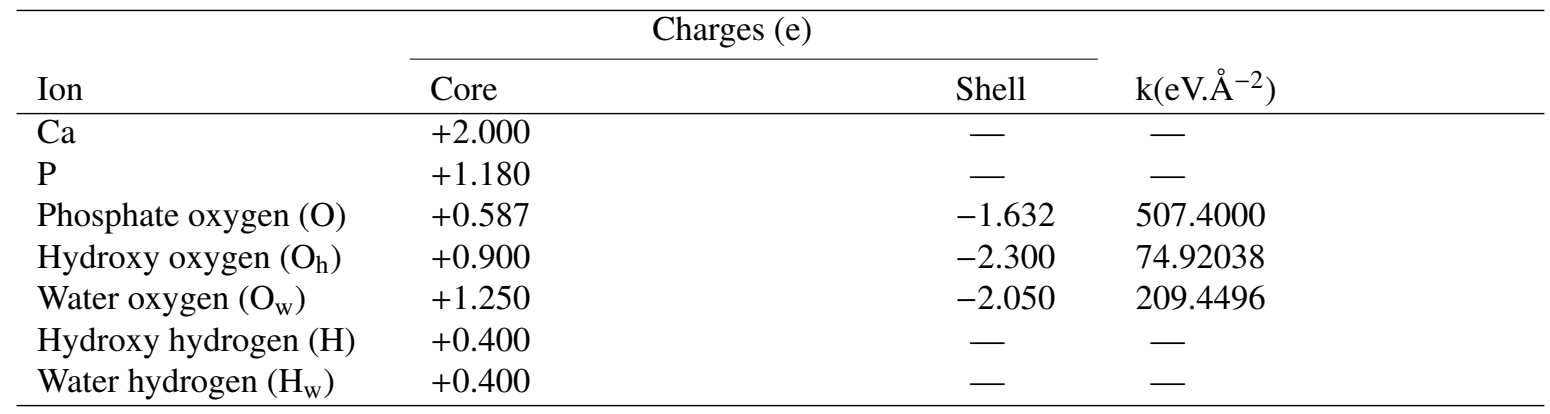

Buckingham potential : $\quad U(r)=A \exp \left(-\frac{r}{\rho}\right)-\frac{C}{r^{6}}$

\begin{tabular}{|c|c|c|c|}
\hline Ion pair & $\mathrm{A}(\mathrm{eV})$ & $\rho(\AA)$ & $\mathrm{C}\left(\mathrm{eV} . \AA^{6}\right)$ \\
\hline $\mathrm{O}($ shell)-O(shell) & 16372.0 & 0.213 & 3.47 \\
\hline $\mathrm{O}\left(\right.$ shell) $-\mathrm{O}_{\mathrm{h}}($ shell $)$ & 22764.0 & 0.149 & 4.92 \\
\hline $\mathrm{O}($ shell $)-\mathrm{O}_{\mathrm{w}}($ shell $)$ & 12533.6 & 0.213 & 12.09 \\
\hline $\mathrm{O}_{\mathrm{h}}\left(\right.$ shell)- $\mathrm{O}_{\mathrm{h}}($ shell $)$ & 22764.0 & 0.149 & 6.97 \\
\hline $\mathrm{O}_{\mathrm{h}}\left(\right.$ shell) $-\mathrm{O}_{\mathrm{w}}($ shell $)$ & 22764.0 & 0.149 & 17.14 \\
\hline $\mathrm{O}($ shell)-H & 312.0 & 0.250 & 0.00 \\
\hline $\mathrm{O}($ shell $)-\mathrm{H}_{\mathrm{w}}$ & 396.27 & 0.230 & 0.00 \\
\hline $\mathrm{O}_{\mathrm{h}}($ shell)-H & 312.0 & 0.250 & 0.00 \\
\hline $\mathrm{O}_{\mathrm{h}}($ shell $)-\mathrm{H}_{\mathrm{w}}$ & 311.97 & 0.250 & 0.00 \\
\hline $\mathrm{O}_{\mathrm{w}}$ (shell)-H & 396.27 & 0.250 & 0.00 \\
\hline $\mathrm{O}_{\mathrm{w}}$ (shell)- $\mathrm{H}_{\mathrm{w}}$ & 396.27 & 0.250 & 10.00 \\
\hline $\mathrm{Ca}-\mathrm{O}($ shell) & 1550.0 & 0.297 & 0.00 \\
\hline $\mathrm{Ca}-\mathrm{O}_{\mathrm{h}}($ shell $)$ & 1250.0 & 0.3437 & 0.00 \\
\hline $\mathrm{Ca}-\mathrm{O}_{\mathrm{w}}($ shell $)$ & 1186.6 & 0.2970 & 0.00 \\
\hline
\end{tabular}

Lennard-Jones potential : $\quad U(r)=\left(\frac{A}{r^{12}}-\frac{B}{r^{6}}\right)$

\begin{tabular}{|c|c|c|c|c|}
\hline Ion pair & $\mathrm{A}\left(\mathrm{eV} . \AA^{12}\right)$ & \multicolumn{3}{|c|}{$B\left(e V . \AA^{6}\right)$} \\
\hline $\mathrm{O}_{\mathrm{w}}$ (shell) $-\mathrm{O}_{\mathrm{w}}($ shell $)$ & 39344.98 & 42.150 & & \\
\hline Morse potential : & $U(r)=D(1$ & & & \\
\hline Ion pair & $\mathrm{D}(\mathrm{eV})$ & $\alpha\left(\AA^{-1}\right)$ & $r_{0}(\AA)$ & $\begin{array}{l}\text { Coulombic } \\
\text { subtraction(\%) }\end{array}$ \\
\hline $\mathrm{P}-\mathrm{O}$ (core) & 3.47 & 1.900 & 1.600 & 0 \\
\hline $\mathrm{H}-\mathrm{O}_{\mathrm{h}}($ shell $)$ & 7.0525 & 3.1749 & 0.9485 & 100 \\
\hline $\mathrm{H}_{\mathrm{w}}-\mathrm{O}_{\mathrm{w}}$ (shell) & 6.0203713 & 0.92367 & 2.22003 & 50 \\
\hline $\mathrm{H}_{\mathrm{w}}-\mathrm{H}_{\mathrm{w}}$ & - & - & - & 50 \\
\hline
\end{tabular}

Three-body potential : $\quad U(\theta)=\frac{k}{2}\left(\theta-\theta_{0}\right)^{2}$

\begin{tabular}{lll}
\hline Ion group & $k\left(\mathrm{eV} \cdot \mathrm{rad}^{-2}\right)$ & $\theta_{0}\left(^{\circ}\right)$ \\
\hline $\mathrm{O}($ core $)-\mathrm{P}-\mathrm{O}($ core $)$ & 1.322626 & 109.47 \\
$\mathrm{H}_{\mathrm{w}}-\mathrm{O}_{\mathrm{w}}($ shell $)-\mathrm{H}_{\mathrm{w}}$ & 4.19978 & 108.6932 \\
\hline
\end{tabular}




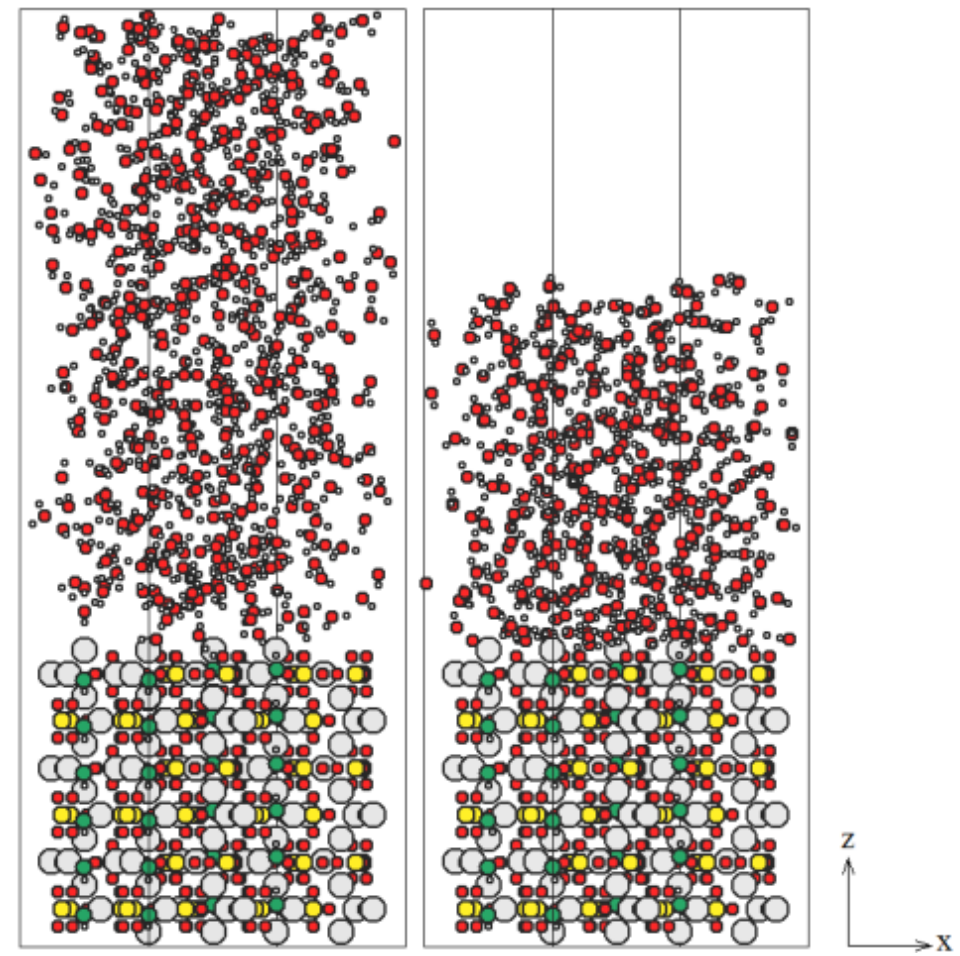

Fig. 2 Side view of the water-HAP simulation box at the beginning (left) and after $100 \mathrm{ps}$ in NVE ensemble (right) $(\mathrm{Ca}=$ gray, $\mathrm{P}=$ yellow, $\mathrm{O}_{\text {phosphate }}$ and $\mathrm{O}_{\text {water }}=$ red, $\mathrm{O}_{\mathrm{OH}}=$ green, $\mathrm{H}=$ white). The number of initial water molecules will a posteriori determine the inter-platelet distance (see color online).

$\mathrm{O}-\mathrm{H}$ angle of the water monomer, and the structure of the water dimer [19]. The directionality of the covalent bonds with the experimental H-O-H angle is reproduced via a Morse potential. The long-range electrostatic interactions between the charges of all species were computed using the Smoothed Particle Mesh Ewald (SPME) method with the acceptable relative error of $10^{-6}$ [20]. All our simulations were performed with the molecular dynamics code DL-POLY 4.5 [21]. The integration algorithms are based on a Verlet leap-frog scheme. Because of the small mass of the shell, a small time step of 0.1 fs was used to maintain the system stability. Periodic boundary conditions were applied in all directions of the box. Figure 2 shows the side view of the water-HAP simulation box at the beginning (left) and after 100 ps in NVE ensemble (right) $\left(\mathrm{Ca}=\right.$ gray, $\mathrm{P}=$ yellow, $\mathrm{O}_{\text {phosphate }}$ and $\mathrm{O}_{\text {water }}=$ red, $\mathrm{O}_{\mathrm{OH}}=$ green, $\mathrm{H}=$ white). Note that this figure (right) shows the configuration in NVE ensemble a little bit before the switch in NPT ensemble. The number of initial water molecules will a posteriori determine the inter-platelet distance (see color online). More precisely, the simulation method corresponds to a two-step strategy: initially, it runs under 
NVE conditions for $100 \mathrm{ps}$ to equilibrate the system, then switches to NPT conditions at different temperatures and $p=1 \mathrm{~atm}$, with anisotropic pressure scaling, so that each side of the simulation box changes independently. After 50 ps equilibration in the NPT ensemble, the data collections are performed for at least 500 ps. We have used the Nosé-Hoover algorithm for the thermostat and barostat, as this algorithm can be performed under both NVT and NPT conditions, thus keeping the simulations consistent, with relaxation times of $0.5 \mathrm{ps}$ [22]. Following the methodology used by de Leeuw [17], we have set the simulation temperature at $310 \mathrm{~K}$, and we verified that the temperature fluctuated by less than $10 \mathrm{~K}$ during the production period, which was of at least $500 \mathrm{ps}$ for all systems considered in the present study. The production run produces the system properties at each $1 \mathrm{fs}$, including structure, averaged properties, which are used to compute the atom densities, radial distribution functions. The root mean square displacements of the atoms are sampled every $1 \mathrm{ps}$ to determine the self-diffusion coefficients. In addition to those static analyses, hydrodynamics simulations can also be performed to mimic a Poiseuille flow in the nanopore by application of an external driving force in order to obtain the parabolic velocity profiles after at least $1 \mathrm{~ns}$ (see section 3.4).

\subsection{Justification of the interatomic potential model}

The polarizable shell-model water potential [16] used in the present study has proven successful in describing the structure of liquid water in contact with biominerals such as calcite [23] and aragonite [24] $\left(\mathrm{CaCO}_{3}\right)$, and dolomite $\left[\mathrm{MgCa}\left(\mathrm{CO}_{3}\right)_{2}\right][25]$ compared with other standard non-polarizable potentials, the shell-water model has been specificcally developed to model solid-liquid interfaces $[16,23]$. For example, the values of the surface calciumwater distances of calcite obtained using the polarizable model are in very good agreement with experimental data and ab initio calculations, as well as with other water potential models (see Tab. 2). Moreover, the $\mathrm{Ca}-\mathrm{O}_{\mathrm{w}}$ distances of $\mathrm{Ca}\left(\mathrm{H}_{2} \mathrm{O}\right)_{n}$ hydrated clusters $(\mathrm{n}=1-8)$ computed using the Ca-water polarizable model is very close to density functional theory calculations [26] (see Fig. 3) and it performs significantly better than other nonpolarizable models (see Fig. 3). The average $\mathrm{O}_{\mathrm{w}}-\mathrm{O}_{\mathrm{w}}$ distance in our bulk water is $2.975 \AA$, which is very close to the experimental value of $2.976 \AA$ obtained from microwave spectroscopy [27]. The number of H-bonds obtained for the core-shell model bulk water (3.8) compares well with the average number of H-bonds obtained from simulations of water using ab initio forces ( $n_{\mathrm{HB}}=3.3$ to 3.8 depending on the type of theory) or other water 
Table 2 Calcium-water distances obtained with the core-shell potential model used in this study, compared with values from molecular dynamics simulations using different water potential models, ab initio calculations and experimental data. The symbol $\equiv$ indicates a surface group; LW (Liquid Water) and ML (Monolayer Coverage).

\begin{tabular}{lll}
\hline & $\equiv \mathbf{C a}-\mathbf{O}_{\text {water }}(\AA)$ & $\mathbf{n}_{\mathbf{H}_{\mathbf{2}} \mathbf{O}}$ \\
\hline Classical MD simulation, core-shell potential [23] & 2.435 & $\mathrm{ML}$ \\
Classical MD simulation [16,18] & 2.4 & $<\mathrm{ML}$ \\
Classical MD simulation [29] & 2.55 & $\mathrm{ML}$ \\
Classical MD simulation [30] & 2.45 & $\mathrm{ML}$ \\
Classical MD simulation [31] & 2.2 & $\mathrm{LW}$ \\
Classical MD simulation [32] & 2.2 & $\mathrm{LW}$ \\
Classical MD simulation [33] & 2.3 & $\mathrm{LW}$ \\
Classical MD simulation [34] & 2.0 & $\mathrm{LW}$ \\
Classical MD simulation [35] & $\sim 2.3$ & $\mathrm{LW}$ \\
ab initio simulation [36] & 2.46 & $<\mathrm{ML}$ \\
ab initio simulation [37] & 2.47 (face) & 1 \\
\hline
\end{tabular}

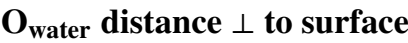

$\equiv$ Ca-coordinated water, core-shell potential [23]

$\equiv$ Ca-coordinated water, surface diffraction [38]

$\equiv$ Ca-coordinated water, X-ray scattering [39]

$\equiv$ Ca-coordinated water, X-ray scattering [40]
$2.41(2.35-2.43)$

$2.35 \pm 0.05$

$2.3 \pm 0.1$

$2.50 \pm 0.12$

potentials, like the TIP3P $\left(n_{\mathrm{HB}}=3.7\right)$ or the extended simple point charge $(\mathrm{SCP} / \mathrm{E})$ potentials $\left(n_{\mathrm{HB}}=3.5[28]\right)(\mathrm{see}$ Tab. 3).

We have also assessed the accuracy of the core-shell interatomic potential model with respect to the hydration energy of the calcium ion. We used the free energy perturbation method [43], in which the calcium ion is made "disappear" in water by gradually switching-off the ion charge and the ion-water interaction terms. This was achieved by conducting thirteen independent, consecutive MD simulations where the charge on the calcium $q_{\mathrm{Ca}^{2+}}$ was set to:

$$
q_{C a^{2+}}=2 \lambda^{c}
$$

where the parameter $\lambda^{c}$ takes $N_{c}$ intermediate values such that $1.0=\lambda_{0}^{c}>\lambda_{1}^{c}>\ldots>\lambda_{N_{c}-1}^{c}>\lambda_{N_{c}}^{c}=0.0$. For the MD simulations, we choose $N_{c}=13$ and $\lambda_{i}^{c}$ taking its value in the ordered set $\mathcal{S}_{c}$ defined by:

$$
\mathcal{S}_{c}=\{1.0,0.9,0.8,0.7,0.6,0.5,0.4,0.3,0.2,0.1,0.05,0.01,0.0\}
$$




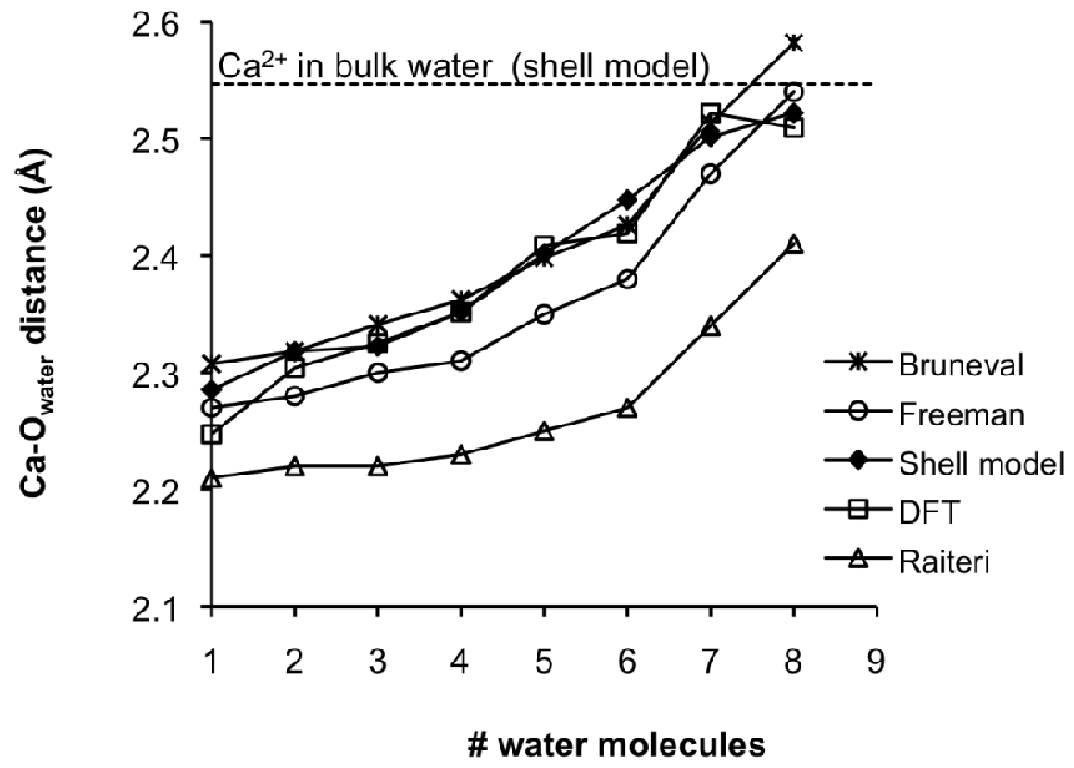

Fig. 3 Distance between $\mathrm{Ca}^{2+}$ and oxygen in water molecule versus number of water molecules. Shell model results ( $\downarrow$, dashed line) [23] were obtained using the core shell model employed in this study; ( $\square$ ) Density Functional Theory results [26]; (*) results from MD simulations using polarizable potential (SWM4-NDP) [41]; (O) polarizable potential model [42], $(\triangle)$ Raiteri force field [34].

Table 3 Distribution of the number of hydrogen-bonds per water molecules for the water molecules that are part of the first hydration shell of the calcium ion and for bulk water. Values obtained using the polarizable core-shell model, the non-polarizable TIP3P water model, and $a b$ initio methods [23]. Temperature is $300 \mathrm{~K}$ unless otherwise stated. The values given are percentages of molecules with the given number of hydrogen-bonds [28].

a range of average HBs for different density functionals [42];

b 518 water molecules using DL POLY.

\begin{tabular}{ccccccccc}
\hline & \multicolumn{7}{c}{ Number of hydrogen-bonds } \\
\hline $\mathbf{C a}^{\mathbf{2 +}}$ in water & $\mathbf{0}(\%)$ & $\mathbf{1}(\%)$ & $\mathbf{2}(\%)$ & $\mathbf{3}(\%)$ & $\mathbf{4}(\%)$ & $\mathbf{5}(\%)$ & $\mathbf{6}(\%)$ & average \\
\hline $\mathrm{T}=300 \mathrm{~K}$ (shell model) & 1.1 & 12.0 & 45.4 & 29.5 & 10.0 & 2.0 & 0.1 & 2.42 \\
$\mathrm{~T}=320 \mathrm{~K}$ (shell model) & 1.2 & 15.4 & 44.6 & 28.2 & 9.0 & 1.5 & 0.1 & 2.34 \\
$\mathrm{~T}=340 \mathrm{~K}$ (shell model) & 1.1 & 16.7 & 42.4 & 28.3 & 9.3 & 2.3 & 0.0 & 2.35 \\
$\mathrm{~T}=400 \mathrm{~K}$ (shell model) & 2.6 & 20.4 & 46.6 & 23.3 & 6.1 & 1.0 & 0.0 & 2.13 \\
$\mathrm{~T}=$ 400 K (ab initio)[23] & 0.1 & 15.5 & 51.4 & 31.7 & 1.3 & 0.0 & 0.0 & 2.19 \\
\hline Pure water & & & & & & & & 3.79 \\
\hline Bulk water (shell model) & 0.2 & 2.1 & 10.6 & 27.2 & 34.2 & 20.0 & 5.8 & $3.84^{\mathrm{a}}$ \\
Bulk water (ab initio MD) & & & & & & & & $3.65^{\mathrm{b}}$ \\
Bulk water (TIP3P) & 0.2 & 0.8 & 7.1 & 28.9 & 52.3 & 10.3 & 0.5 &
\end{tabular}


This was followed by other $N_{v}=12 \mathrm{MD}$ simulations where the Buckingham interaction was gradually switched off using a dumping parameter $\lambda_{i}^{v}$, which value was in the ordered set $\mathcal{S}_{v}$ defined by:

$$
\mathcal{S}_{v}=\{0.9,0.8,0.7,0.6,0.5,0.4,0.3,0.2,0.1,0.05,0.01,0.0\}
$$

Note that the value $\lambda_{0}^{v}=1.0$ is missing because this correspond to the MD simulation where $\lambda_{N_{c}}^{c}=0.0$.

The free energy difference of hydration $\Delta G_{\text {hyd }}$ was then evaluated using the following expression:

$$
\Delta G_{h y d}=-\frac{1}{\beta}\left(\sum_{i=0}^{N_{c}-1} \Delta G_{i}\left(\lambda_{i}^{c}\right)+\sum_{i=0}^{N_{v}-1} \Delta G_{i}\left(\lambda_{i}^{v}\right)\right),
$$

where

$$
\Delta G_{i}\left(\lambda_{i}^{c}\right)=G_{i}\left(\lambda_{i+1}^{c}\right)-G_{i}\left(\lambda_{i}^{c}\right), \quad \Delta G_{i}\left(\lambda_{i}^{v}\right)=G_{i}\left(\lambda_{i+1}^{v}\right)-G_{i}\left(\lambda_{i}^{v}\right)
$$

Note that the value associated with $\lambda^{c}=1$ and $\lambda^{v}=1$ corresponds to $\mathrm{Ca}^{2+}$, and the state associated with $\lambda^{c}=0$ and $\lambda^{v}=0$ corresponds to Neon. The free energy difference associated with each intermediate state is given by:

$$
\left.\Delta G_{i}\left(\lambda_{i}^{\alpha}\right)=-\frac{1}{\beta} \ln \left\langle\exp \left[-\beta\left(U^{a v}\left(\lambda_{i+1}^{\alpha}\right)-U\left(\lambda_{i}^{\alpha}\right)\right)\right)\right]\right\rangle_{\lambda_{i}^{\alpha}}, \quad \text { for } \alpha=c, v,
$$

where In designates the natural logarithm function, the angle brackets $\langle\bullet\rangle$ are used to denote a configurational averaging over the ensemble of configurations representative of the initial state of the system defined by the dumping parameter $\lambda_{i}^{\alpha}, U\left(\lambda_{i}^{\alpha}\right)$ is the configurational energy and $\beta=\frac{1}{k T}$ in which $k$ is the Boltzmann constant and $T$ is the temperature. Moreover, in Eq. (4), $U^{a v}\left(\lambda_{i+1}^{\alpha}\right)$ is the average configurational energy of the simulation controlled by the parameter $\lambda_{i+1}^{\alpha}$. For every value of $\lambda_{i}^{\alpha}$, MD simulations of one calcium ion in 2027 water molecules were performed for $200 \mathrm{ps}$, and the simulations were conducted sequentially. The free energy of hydration of $\mathrm{Ca}^{2+}$ obtained using this approach is $-310 \mathrm{kcal} \cdot \mathrm{mol}^{-1}$, which is close to the values of free energy obtained using the Buckingham Ca- $\mathrm{O}_{\mathrm{w}}$ along with the rigid TIP4P and TI3P water models $\left(309 \mathrm{kcal}^{\mathrm{mol}}{ }^{-1}\right)$ [34]. This value is approximately $10 \%$ lower than the experimental hydration free energy measured by David et al. [44] (whose the value is $345 \mathrm{kcal} . \mathrm{mol}^{-1}$ ).

The ability of the core-shell potential model to describe the dynamics of the water molecules coordinated to $\mathrm{Ca}^{2+}$ was determined by applying the "direct approach" proposed by Hofer and co-workers [45]: the whole MD 
trajectory was scanned for movements of water molecules, either entering or leaving a coordination shell of the calcium ion, and whenever a water molecule crossed the boundaries of this shell, its path was followed and if its new position outside/inside the shell lasted for more than a time parameter $t^{*}$, then the event was accounted as "real". For the time parameter $t^{*}$ we have chosen the value of $0.5 \mathrm{ps}$ because this has been shown to give a good measure of ligand exchange processes $[45,46]$. The mean residence time (MRT) of water molecules was computed using the following expression:

$$
M R T=\frac{t_{s i m} \times C N_{a v}}{N_{e x}}
$$

where $t_{s i m}$ was the simulation time (800 ps), $C N_{a v}$ the average coordination number of calcium (8.25) and $N_{e x}$ the number of accounted exchange events (640) obtained from the MD simulation of $\mathrm{Ca}^{2+}$ in water. The MRT

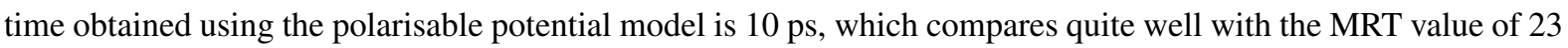
ps obtained from $a b$ initio simulations of $\mathrm{Ca}^{2+}[46]$. In fact, the MRT obtained using a non-polarizable calciumwater Lennard Jones interaction potential [47] with the rigid SPC/E water model [48] was found to be significantly higher (217 ps).

\section{Results and discussion}

\subsection{Local density profile of water}

Figure 4-a reports the number density profiles of the oxygen and hydrogen atoms of water molecules for the pore with a size $H \equiv 80 \AA$. The corresponding mass density profile of water is also shown (Fig. 4-b). Density distributions for other pore sizes $(H \equiv 40 \AA$ and $H \equiv 60 \AA)$ do not display significant differences from those reported in Fig. 4. In proximity to the surface, the strong interaction with the calcium and phosphate ions decreases the mobility of water and leads to the formation of three hydration layers. In the central zone of the channel, the density oscillates around the value of $1.28 \mathrm{~g} \cdot \mathrm{cm}^{-3}$, which is a quarter higher than the experimental density of water, but comparable to the value of $1.25 \mathrm{~g} . \mathrm{cm}^{-3}$ reported by Pan et al. [49] in a molecular dynamics study of rigid nonpolarizable SPC water in contact with the (001) and (100) crystal faces of HAP. It should be mentioned that the high density is a feature of the water core-shell model and was reported in the original paper by de 

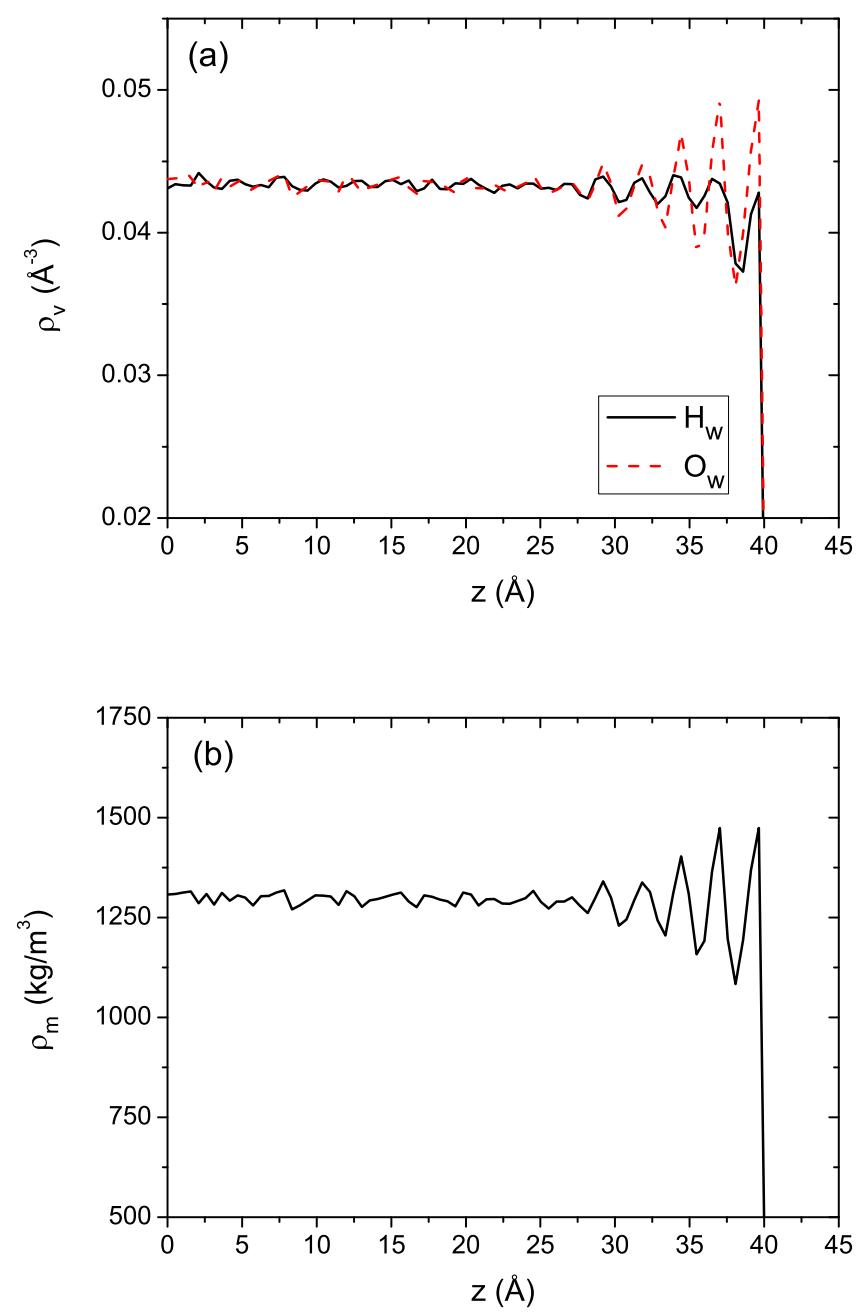

Fig. 4 (a) Number density profiles of water oxygen $\mathrm{O}_{w}$ (dashed line) and water hydrogen atoms $\mathrm{H}_{\mathrm{w}}$ (solid line) in half of the channel crosssection for a pore size $H \equiv 80 \AA$ A. The hydrogen density was divided by a factor two. (b) Mass density profile of water for the corresponding case (see color online).

Leeuw and Parker [16], and even ab initio MD simulations in the framework of density functional theory yields over-structured liquid water compared to experiment [50]. 
3.2 Structural properties of confined water in the bulk and at the interface

A snapshot from the MD simulations of water confined between two platelets of HAP (Fig. 2) (right) shows the interactions between water molecules and the phosphate and calcium ions, where it is possible to observe molecules of the solvent being able to penetrate into the hydroxyl group channels at the surface. However, more quantitative information regarding the structural properties of water in the bulk and at the interface with HAP can be determined by the radial pair distribution function (RDF), $g_{\alpha \beta}(r)$, which represents the probability, relative to a random distribution, of finding an atom of type $\beta$ at a distance $r$ from an atom of type $\alpha$ :

$$
g_{\alpha \beta}(r)=\frac{V}{N_{\beta}} \frac{n_{\alpha \beta}(r)}{4 \pi r^{2} \Delta r}
$$

where $n_{\alpha \beta}(r)$ is the number of atoms of type $\beta$, which are in the spherical layer $\Delta r$ at the distance $r$ from the atoms of type $\alpha, N_{\beta} / V$ is the average density of atoms of type $\beta$. To simplify, the RDF will be denoted $g(r)$ in the graphics.

The RDFs for the oxygen-oxygen (on the one hand), oxygen-hydrogen and hydrogen-hydrogen (on the other hand) pairs of the confined water molecules in thickness layer of $10 \AA$ located in the central zone of the channel as computed from MD simulations at different temperatures are reported in Figs. 5 and 6, respectively.

Regarding the temperature effect, as expected, the peak heights are slightly reduced when the temperature increases, in agreement with previous works using SPC/E, SPC/Fw and TIP4P/2005 models [51,52]. At 298 K, the RDF between oxygen atoms shows two peaks centred at $2.98 \AA$ and $5.7 \AA$, with the respective maximal values of 3.6 and 1.3 (see Fig. 5). This result can be compared to the experimental values for bulk water of 3.1 and 1.1 [53]. Similarly, the peaks of oxygen-hydrogen RDF at $2.12 \AA$ and $3.23 \AA$ are in agreement with experimental values of $1.9 \AA$ and $3.2 \AA$ (see Fig. 6). The peak values of 0.85 and 1.3 are also comparable with the experimental ones of 1.0 and 1.3 [53]. Finally, the hydrogen RDF profile presents a peak at $2.6 \AA$ with a maximal value of 1.3. Another peak is also observed at $5.7 \AA$ of height 0.99 . This values compares well with the experimental peak positions at $2.3 \AA$ and $4.9 \AA$ of height 1.3 and 1 , respectively. In conclusion, the RDF for the atoms of water molecules obtained with the core-shell model exhibit a good agreement with the experimental ordering of bulk liquid water. 


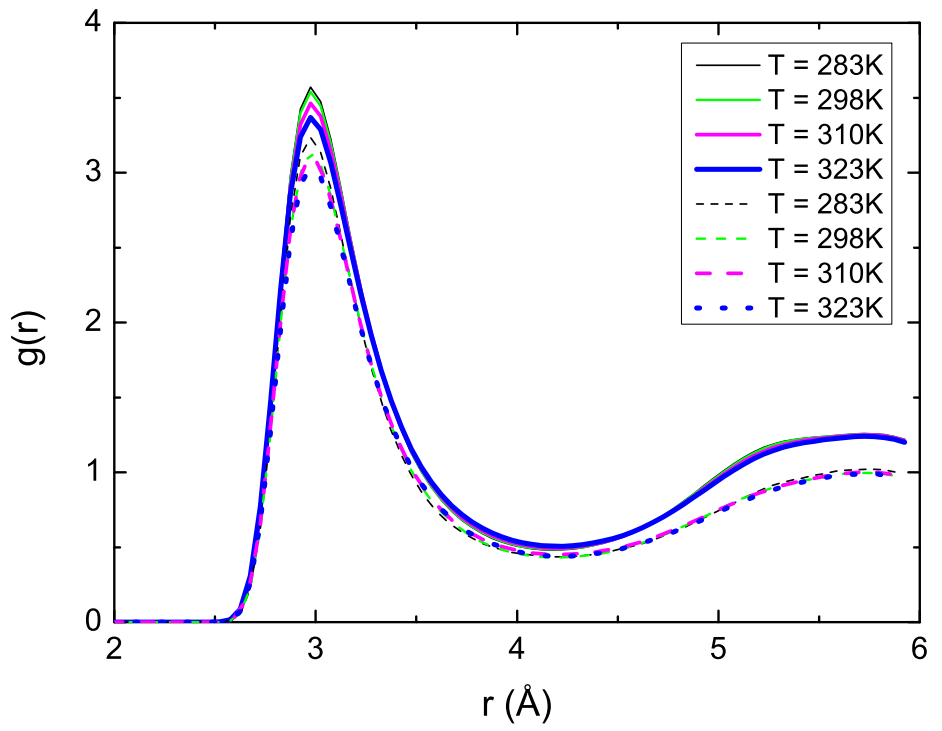

Fig. 5 Oxygen-oxygen of water molecules RDF at different temperatures. The solid lines show the RDF in a thickness water layer of $10 \AA$ located in the central zone of the channel. The dashed lines present the RDF in a thickness water layer of $5 \AA$ adjacent to the HAP surface (see color online).

However, more relevant to this work is the effect of HAP on the structure of water that is coordinated to the surface. In Fig. 5 we have therefore reported the oxygen-oxygen RDFs for the layer of water molecules that are at a distance of less than $5 \AA$ from the HAP surface; this corresponds to the first two layers of water on the surface of HAP (see Fig. 4-b). These profiles show a significant decrease of the first and second maxima, which we related to a reduction in the number of hydrogen bonds because of the interactions of the water molecules with the calcium and phosphate ions at the surface.

To quantify the interactions of liquid water with the surface of HAP we have computed the RDFs between calcium ions and water oxygen atoms $\left(\mathrm{O}_{\mathrm{w}}\right)$, and the RDFs between oxygen atoms of the phosphate groups $(\mathrm{O})$ with water hydrogen atoms $\left(\mathrm{H}_{\mathrm{w}}\right)$ (see Fig. 7). Again, the temperature only slightly changes these profiles. The first peak of these two RDF profiles correspond to the water molecules adsorbed to the HAP surface, and they are respectively centred at $2.43 \AA$ for the $\mathrm{Ca}-\mathrm{O}_{\mathrm{w}}$ pair and $1.88 \AA$ for the $\mathrm{O}-\mathrm{H}_{\mathrm{w}}$ pair. These values are in good agreement with comparable simulations dealing with solvated Ca ions [54], and phosphate groups [55]. The second peak in 


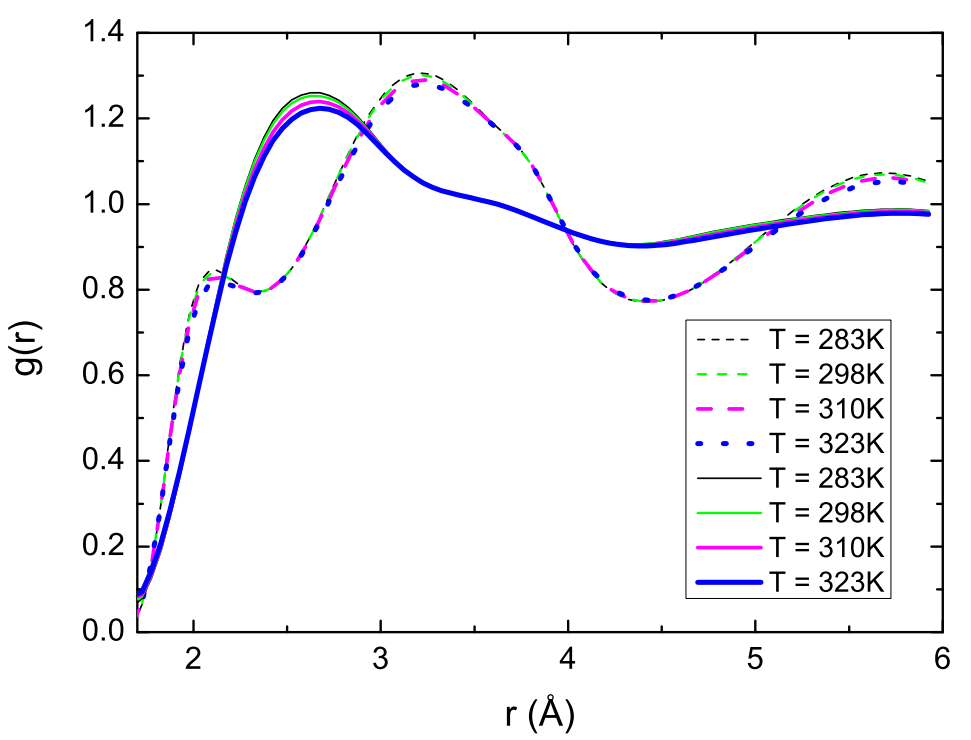

Fig. 6 Oxygen-hydrogen (dashed lines) and hydrogen-hydrogen (solid lines) RDF at different temperatures of water molecules in a thickness layer of $10 \AA$ located in the pore center.

the $\mathrm{Ca}-\mathrm{O}_{\mathrm{w}}$ and $\mathrm{P}-\mathrm{H}_{\mathrm{w}}$ profiles corresponds to the second layer of water and it is interesting to notice that both RDFs display a structuring that is not present in the pair distribution functions of $\mathrm{Ca}-\mathrm{O}_{\mathrm{w}}$ and $\mathrm{P}-\mathrm{H}_{\mathrm{w}}$ obtained from $\mathrm{MD}$ simulations of aqueous solutions of $\mathrm{Ca}^{2+}[46]$ and $\mathrm{PO}_{4}^{3-}$ [55]. For example, the structure of the second peak in the $\mathrm{Ca}-\mathrm{O}_{\mathrm{w}} \mathrm{RDF}$ is given by the convolution of two peaks centred at approximately 4.25 and $5 \AA$, respectively. We relate this to the layering of water on the surface of HAP, which is more pronounced that what observed in aqueous solutions containing isolated calcium and phosphate ions.

\subsection{Self diffusion coefficients of water}

An important dynamical property of the confined liquid that can be obtained from MD simulation is the selfdiffusion coefficient $(D)$ of water, which is given by the slope of the mean-squared displacement (MSD) of the 


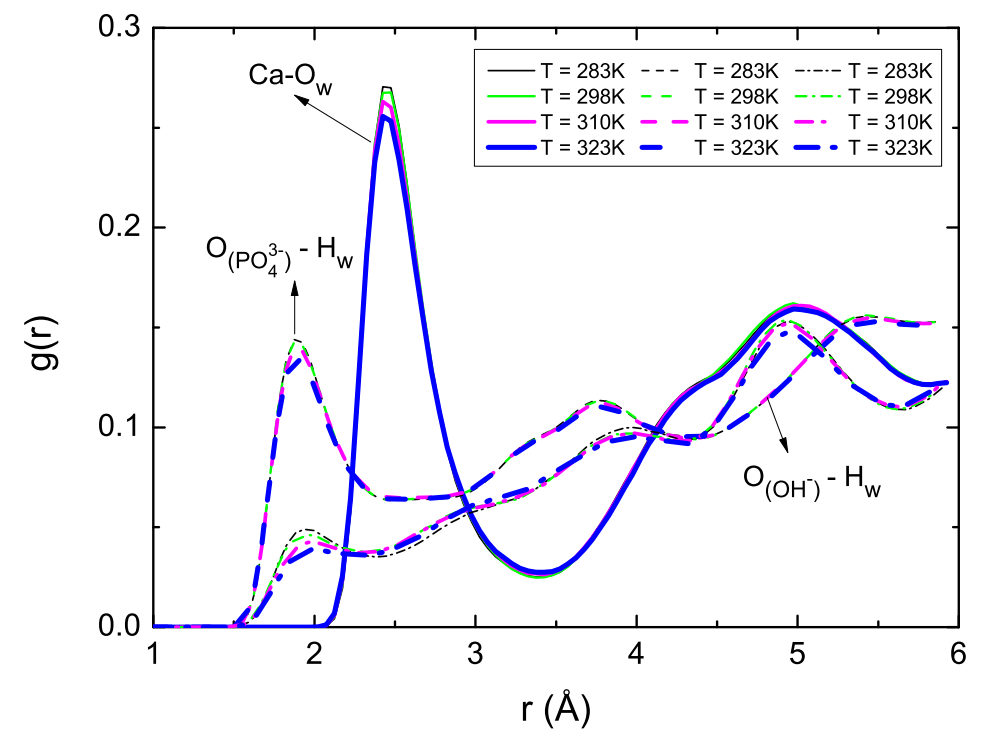

Fig. 7 RDF between calcium ions and water oxygen atoms (solid lines), oxygen atoms of the phosphate groups and water hydrogen atoms (dashed lines), oxygen atoms of the hydroxyl groups and water hydrogen atoms (dash-dotted lines) at different temperatures.

oxygen atoms [56]:

$$
\left\langle\Delta r^{2}(t)\right\rangle=\frac{1}{N_{O_{W}}} \sum_{i=1}^{N_{O_{W}}}\left(\mathbf{r}_{i}(t)-\mathbf{r}_{i}(0)\right)^{2},
$$

where $\mathbf{r}_{i}(0)$ and $\mathbf{r}_{i}(t)$ are respectively the initial position vector and the position vector at time $t$ of the $i$-th oxygen atom, $N_{O_{W}}$ is the number of $O_{W}$ atoms. The diffusion coefficient of water can then be obtained by applying the Einstein equation $\left\langle\Delta r^{2}(t)\right\rangle=6 D t$. The variation of the MSD as a function of time, for different distances $(H)$ between the two platelets of HAP, are illustrated in Fig. 8. We verified that the simulations were sufficiently long to ensure the convergence of the slope of the MSD.

Figure 9 displays the dependence of $D$ on the temperature $T$ and the size of the pore, which shows that the self-diffusion coefficients increase with the temperature applied to the system (for $H \equiv 60 \AA, D$ changes from $0.83 \times 10^{-9} \mathrm{~m}^{2} \cdot \mathrm{s}^{-1}$ at $T=293 \mathrm{~K}$ to $1.81 \times 10^{-9} \mathrm{~m}^{2} \cdot \mathrm{s}^{-1}$ at $\left.323 \mathrm{~K}\right)$. More relevant to this study is the variation of the self-diffusion coefficient with the size of the pore. For instance, at $310 \mathrm{~K}$ the value of $D$ changes from $0.78 \times 10^{-9} \mathrm{~m}^{2} . \mathrm{s}^{-1}$ to $1.4 \times 10^{-9} \mathrm{~m}^{2} \cdot \mathrm{s}^{-1}$ as the distance between the two platelets of HAP increases from 20 to 


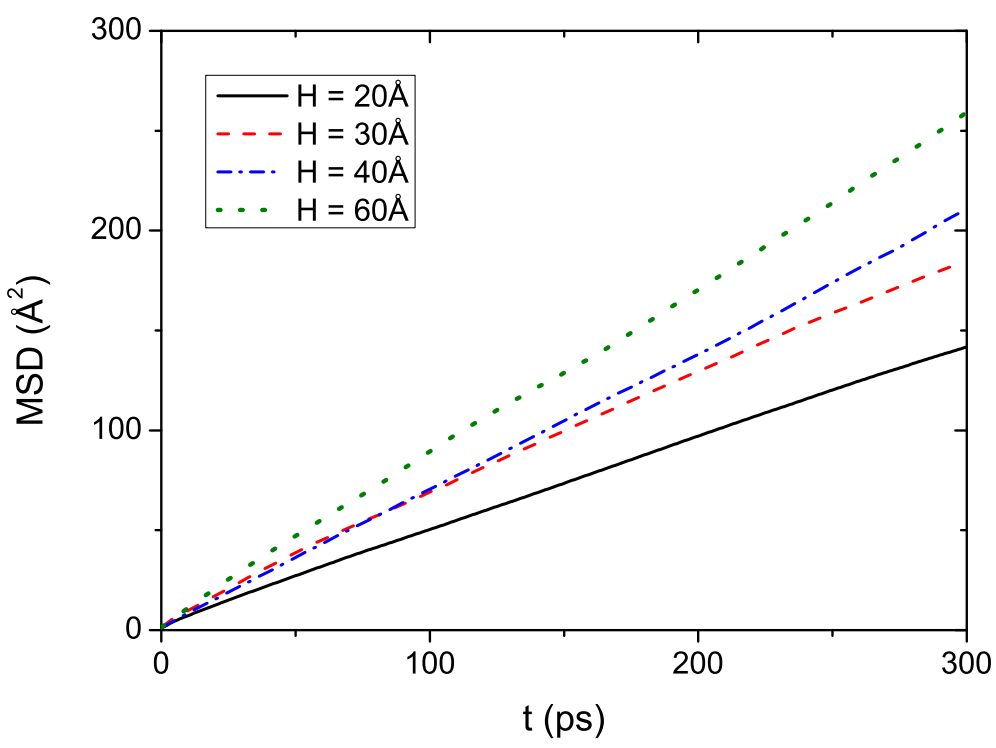

Fig. 8 Mean-squared displacements of water oxygen atoms for different pore sizes at $310 \mathrm{~K}$.

$60 \AA$ A. At the molecular-level, this can be explained in terms of the interactions occurring between the molecules of the solvent and the ions of the HAP surface: for small values of the inter-platelets distance $H$ a significant proportion of water molecules are coordinated to the phosphate and/or calcium ions of the HAP surface. These molecules have a reduced mobility compared to bulk water because the mean residence time of water in the solvation shell of another water molecule is approximately 25 larger then the mean residence time of water in the first coordination shell of a calcium ion [45].

As the size of the pores increases so does the proportion of water molecules that are above the three layers of adsorbed water molecules (see the density profiles in Fig. 4) and that have therefore a bulk-like behaviour.

In order to determine the extent of the confinement's effect on the dynamics of water, we have to compare the self-diffusion coefficients reported in Fig. 9 with the diffusion coefficient in the bulk water. To pursue this analysis, we have conducted a series of MD simulations of liquid water in a cubic cell where the length of each side $L$ was set to 20,30,50 and $60 \AA$. From these simulations the size-independent diffusion coefficient of bulk water can then 


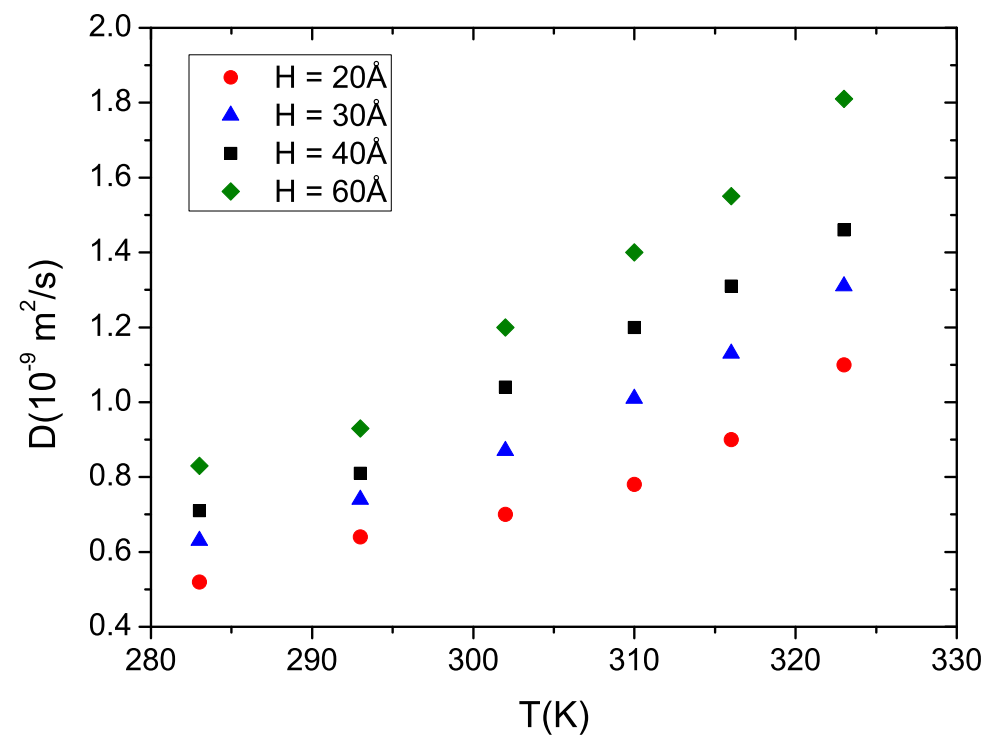

Fig. 9 Self-diffusion coefficients for water calculated at different temperatures and different pore sizes.

be calculated using the following equation $[57,58]$ :

$$
D_{0}=D_{p b c}^{L}+\frac{2.837 k_{B} T}{6 \pi \eta L}
$$

where $D_{p b c}^{L}$ is the diffusion coefficient determined using the periodic boundary conditions and a cubic cell of size $L, k_{B}$ is the Boltzmann constant, $T$ is the temperature and $\eta$ is the viscosity of bulk water. As the viscosity is not known, $D_{0}$ can be estimated from the linear extrapolation of $D_{p b c}^{L}$ with respect to $1 / L$. In fact, Fig. 10 shows that the computed values of $D_{p b c}^{L}$ depend linearly on the inverse of the box size $1 / L$, and the size-independent diffusion coefficient of bulk water corresponds to the value of $D_{p b c}^{L}$ as $1 / L \longrightarrow 0: 1.24 \times 10^{-9} \mathrm{~m}^{2} . \mathrm{s}^{-1}$ at $293 \mathrm{~K}$, $1.45 \times 10^{-9} \mathrm{~m}^{2} \cdot \mathrm{s}^{-1}$ at $302 \mathrm{~K}$ and $2.13 \times 10^{-9} \mathrm{~m}^{2} \cdot \mathrm{s}^{-1}$ at $310 \mathrm{~K}$.

The comparison of the diffusion coefficients of liquid water in the nanopores (see Fig. 9) with the diffusion of bulk water (Fig. 10) clearly shows that the confinement of water has a significant effect on its dynamical properties. For example, at $310 \mathrm{~K}$ and for the largest of the nanopore considered in this study $(H \equiv 60 \AA)$, the diffusion coefficient of water decreases by approximately $30 \%$. 


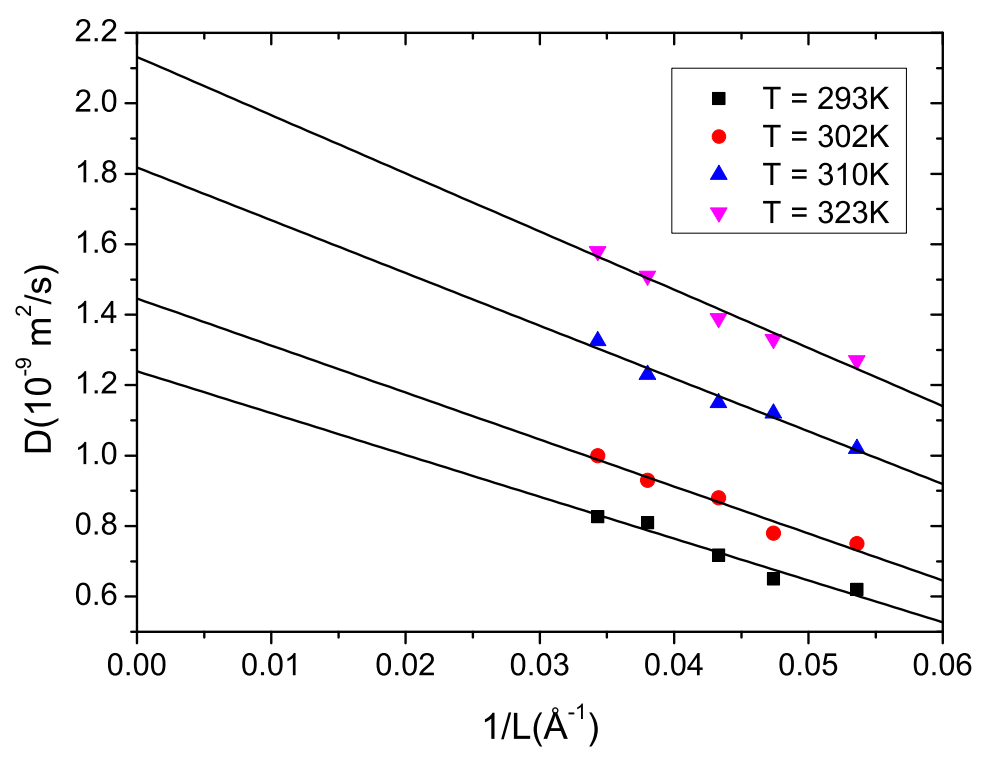

Fig. 10 Self-diffusion coefficients as a function of the inverse box size $1 / L$ at different temperatures. The size-independent diffusion coefficient $D_{0}$ is the extrapolation at $1 / L \rightarrow 0$.

3.4 The shear viscosity of water in bone nanopores

We have computed the shear viscosity $\eta$ of water between the two platelets of HAP using the hydrodynamics and the pressure-shear rate methods [59]. The hydrodynamics approach mimics the Poiseuille flow by applying to each molecule of the fluid a constant external force $f_{x}$ parallel to the surface ( $x$ is here the direction of the flow). Assuming the fluid is a continuous medium with a constant density in the pore, then the Navier-Stokes equation predicts a parabolic velocity profile, from which the shear viscosity $\eta$ can be estimated using the following relation:

$$
\eta=-\frac{\rho_{v} f_{x}}{\left(\frac{d^{2} u_{x}}{d z^{2}}\right)},
$$

where $u_{x}$ is the fluid velocity in the $x$ direction and $\rho_{v}$ is the density of water. The second approach to evaluate fluid viscosity uses the relation between the off-diagonal pressure $P_{x z}(z)=f_{x} \int_{0}^{z} \rho_{v}(\xi) d \xi$ and the local shear-rate 
$d u_{x} / d z:$

$$
\eta(z)=-\lim _{f_{x} \rightarrow 0} \frac{P_{x z}(z)}{\frac{d u_{x}}{d z}} .
$$

Note that the negative of the pressure tensor is called the stress tensor. In the integral definition of the offdiagonal pressure $P_{x z}, z=0$ corresponds to the symmetry plan between the two solid platelets located at $z= \pm H / 2$.

We first report the results obtained using the hydrodynamics approach to estimate the dynamic viscosity of confined water. Thus, after the two-step simulation described in subsection 2.2, each water molecule is submitted to an external force $f_{x}=4.3 \times 10^{-3} \mathrm{kcal} \cdot \mathrm{mol}^{-1} . \AA^{-1}$. This force value was chosen because it gave a good numerical signal to noise ratio in the least expansive time of computational. Note that this value did not affect the calculated viscosity coefficients. We checked that the same values of the viscosity were obtained by performing simulations with smaller values of $f_{x}$. Similar strategies have been successfully used when studying hydrodynamics in clay nanopores [60]. Figures 11, 12 and 13 show the velocity profiles for different inter-platelet distances $(H \equiv 40 \AA$, $H \equiv 60 \AA, H \equiv 80 \AA$ ). . As expected, the profiles have parabolic form and their curvature provides the estimation of fluid viscosity, via Eq. (9): $\eta=0.38 \mathrm{cP}$ for $40 \AA$, $0.40 \mathrm{cP}$ for $60 \AA$ and $0.40 \mathrm{cP}$ for $80 \AA$. These values are $12 \%$ and $7 \%$ lower, respectively, than the viscosity of bulk water, $0.43 \mathrm{cP}$, which was estimated using Eq. (8) at from MD simulations conducted at $310 \mathrm{~K}$.

For the purpose of comparison, we also computed the viscosity from the pressure-shear rate relation (see Eq. (10)). The results are presented in Fig. 14 where the viscosity variations across half of the pore are given for different sizes of the pore. The viscosity is almost uniform across the pore reaching a value around $0.4 \mathrm{cP}$ (except in $z=0$ where the integral term in the definition of the off-diagonal pressure $P_{x z}$ is zero), which is close to the one obtained using the Poiseuille profiles.

The shear viscosities obtained in this work are smaller than the experimental ones (typically $0.652 \mathrm{cP}$, measured at $313 \mathrm{~K}$ and $1 \mathrm{~atm}$ [61] or $0.70 \mathrm{cP}$, obtained from a fit of experimental data [62] at $310 \mathrm{~K}$ ). Recently, using Poiseuille flow in a nano-channel, Markesteijn et al. [63] computed the viscosity of several water models. At $313 \mathrm{~K}$, their values are $0.519 \mathrm{cP}$ for SPC/E, $0.402 \mathrm{cP}$ for TIP4P, $0.538 \mathrm{cP}$ for TIP4P/Ew and $0.586 \mathrm{cP}$ for TIP4P/2005 model [63]. At the same temperature, for bulk water Fanourgakis et al. [64] calculated the shear viscosity of rigid water models via equilibrium MD methods and found a value of $\eta$ of 0.549 for SPC/E, 0.347 for TIP4P and 0.753 for TIP4P/2005. As there are not many simulated data of water viscosity for human in vivo 


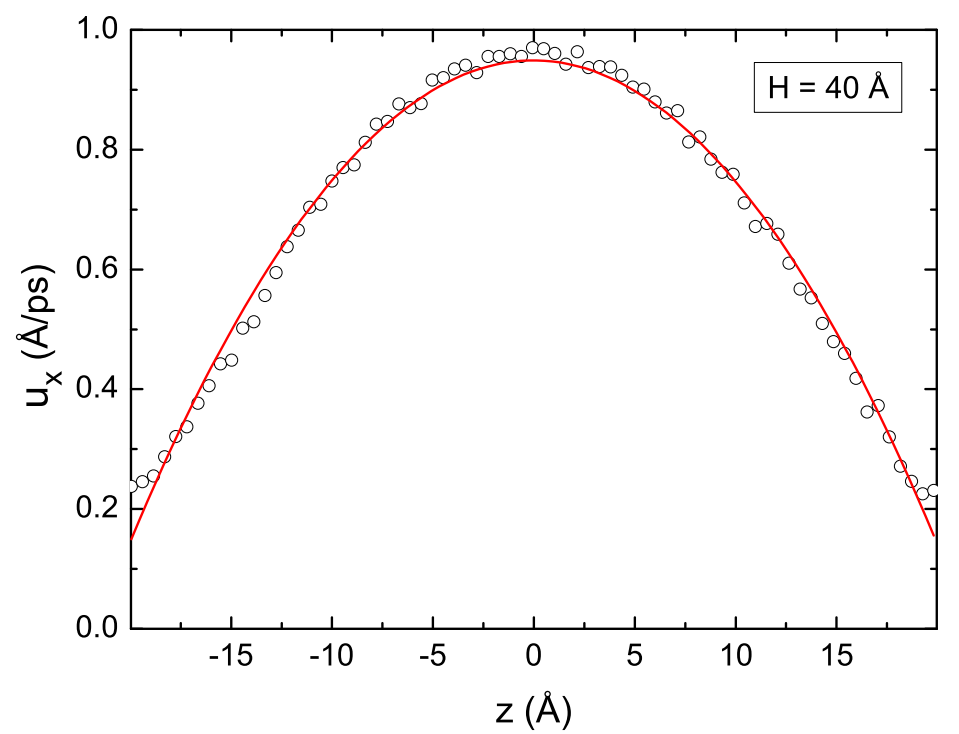

Fig. 11 Velocity profile of water in the case $H \equiv 40 \AA$ A. Points represent the MD data and the solid line is a parabolic fit. The two vertical axes correspond to the location of HAP surfaces.

conditions $(T=310 \mathrm{~K}, p=1 \mathrm{~atm})$, we computed the viscosity at the most used temperature - ambient temperature and compared with the literature.

Table 4 reports previous works on the shear viscosity of water around ambient temperature, using both with equilibrium and non equilibrium methods. It shows a wide difference in different water models. The TIP4P/2005 water model provides the best prediction with the deviation of $4-16 \%$ from the experimental value. The SPC/E model is slightly worse. In general, the errors are about $8-30 \%$. The TIP4P model and SPC model underestimate the value of the viscosity. The deviation falls into the interval of $35-55 \%$ for the SPC model and $37-48 \%$ for the TIP4P model. The viscosity of core shell model obtained in this work is $55 \%$ lower than the experimental value and similar with the values obtained from the TIP4P model. Consequently, it seems that the core-shell water model is not well adapted to the estimation of confined water viscosity since it tends to underestimate its value. 
Table 4 Shear viscosity of different water models from the literature, computed at around ambient temperature [65].

\begin{tabular}{|c|c|c|c|}
\hline Water model & Temperature $(\mathrm{K})$ & Viscosity $(\mathrm{cP})$ & Reference \\
\hline \multirow[t]{5}{*}{ TIP4P/2005 } & 298 & 0.86 & [66] \\
\hline & 298 & 0.89 & [65] \\
\hline & 298 & 0.807 & [67] \\
\hline & 303 & 0.817 & [63] \\
\hline & 303 & 0.753 & [67] \\
\hline \multirow[t]{8}{*}{ TIP4P } & 298 & 0.48 & [68] \\
\hline & 298 & 0.46 & [68] \\
\hline & 298 & 0.49 & [66] \\
\hline & 298 & 0.47 & [69] \\
\hline & 298 & 0.56 & [65] \\
\hline & 298 & 0.483 & [67] \\
\hline & 303 & 0.479 & [63] \\
\hline & 303 & 0.441 & [67] \\
\hline \multirow{13}{*}{ SPC/E } & 300 & 0.72 & [70] \\
\hline & 298 & 0.66 & [71] \\
\hline & 298 & 0.73 & [66] \\
\hline & 298 & 0.75 & [72] \\
\hline & 298 & 0.82 & [65] \\
\hline & 298 & 0.704 & [67] \\
\hline & 300 & 0.49 & [73] \\
\hline & 300 & 0.64 & [74] \\
\hline & 303 & 0.66 & [75] \\
\hline & 303 & 0.62 & [75] \\
\hline & 303 & 0.65 & [76] \\
\hline & 303 & 0.66 & [63] \\
\hline & 303 & 0.639 & [67] \\
\hline \multirow[t]{6}{*}{ SPC } & 300 & 0.58 & [77] \\
\hline & 298 & 0.49 & [65] \\
\hline & 300 & 0.40 & [70] \\
\hline & 300 & 0.49 & [73] \\
\hline & 300 & 0.40 & [74] \\
\hline & 300 & 0.40 & [74] \\
\hline Core shell & 300 & 0.49 & This work \\
\hline Experiment & 300 & 0.896 & [78] \\
\hline
\end{tabular}




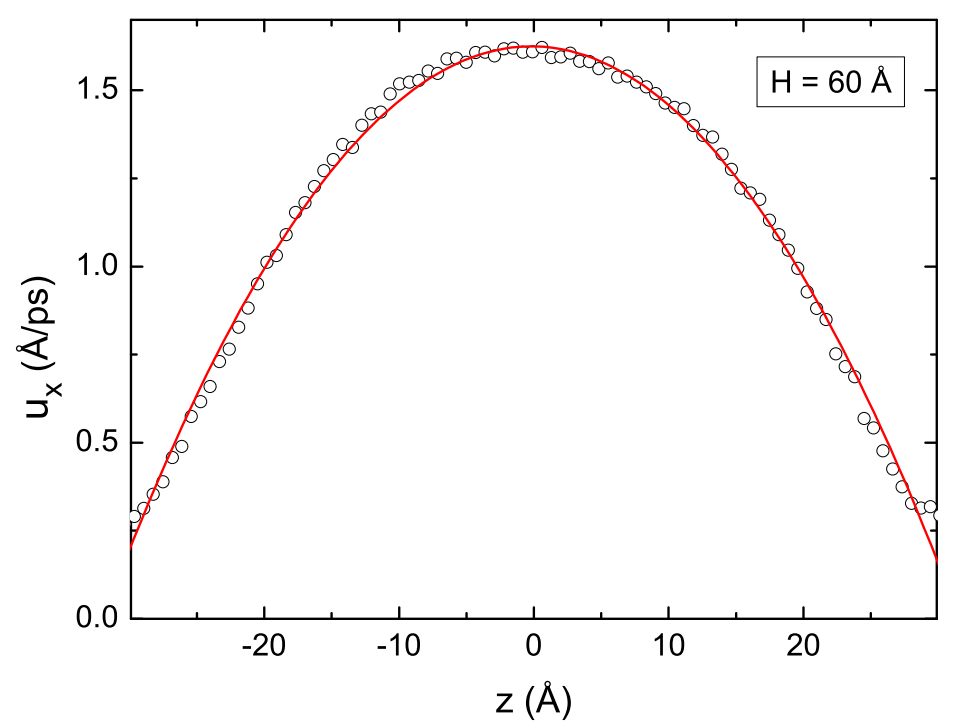

Fig. 12 Velocity profile of water in the case $H \equiv 60 \AA$ A. Points represent the MD data and the solid line is a parabolic fit. The two vertical axes correspond to the location of HAP surfaces.

\subsection{Slip boundary condition}

In most applications concerning a fluid flowing over a solid surface, and especially in the bone fluid flow within the bone porous structure, a no-slip velocity condition is widely used because it is simple and often produces results in agreement with experiments. However, these observations that support the no-slip concept are essentially based on macroscopic evidence, and may not necessarily apply when considering nanoscopic length scales. Over the past decade, many experimental and numerical proofs of a slip phenomenon occurring at the liquid-solid interfaces have been proposed $[79,80]$. Neglecting such a slip phenomenon when quantifying fluid flows at the nanoscale could induce a strong underestimation of its value.

In order to model this effect, a Navier boundary condition, which states that the extent of liquid slip is proportional to the velocity gradient at the wall, should be introduced:

$$
L_{s}=\frac{u_{x}^{s}}{\left(\frac{\partial u_{x}}{\partial z}\right)_{s}}
$$




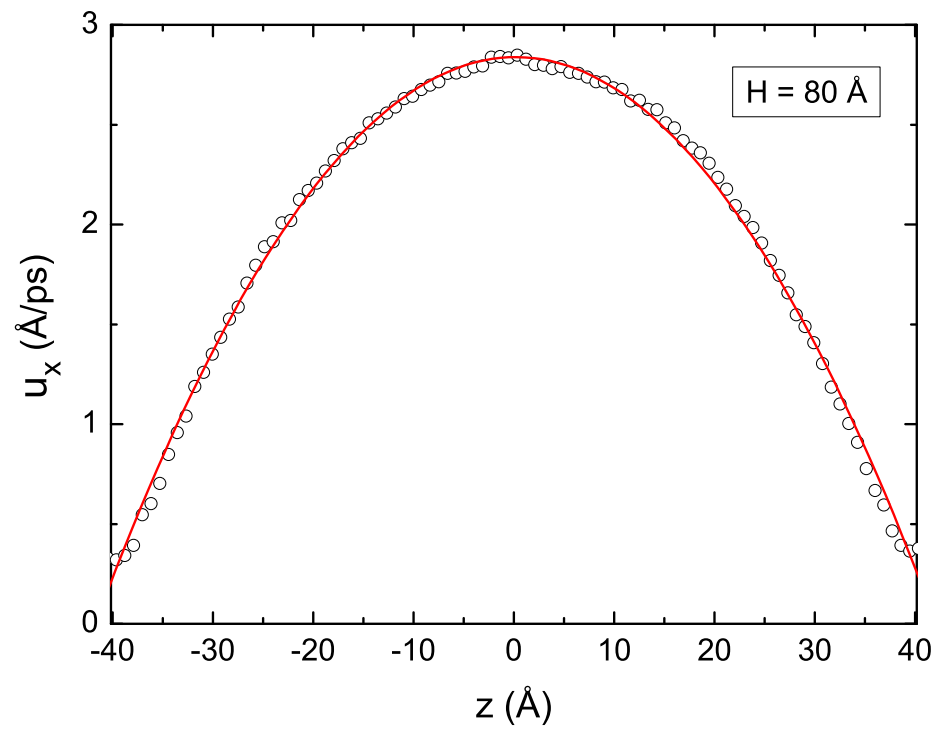

Fig. 13 Velocity profile of water in the case $H \equiv 80 \AA$ A. Points represent the MD data and the solid line is a parabolic fit. The two vertical axes correspond to the location of HAP surfaces.

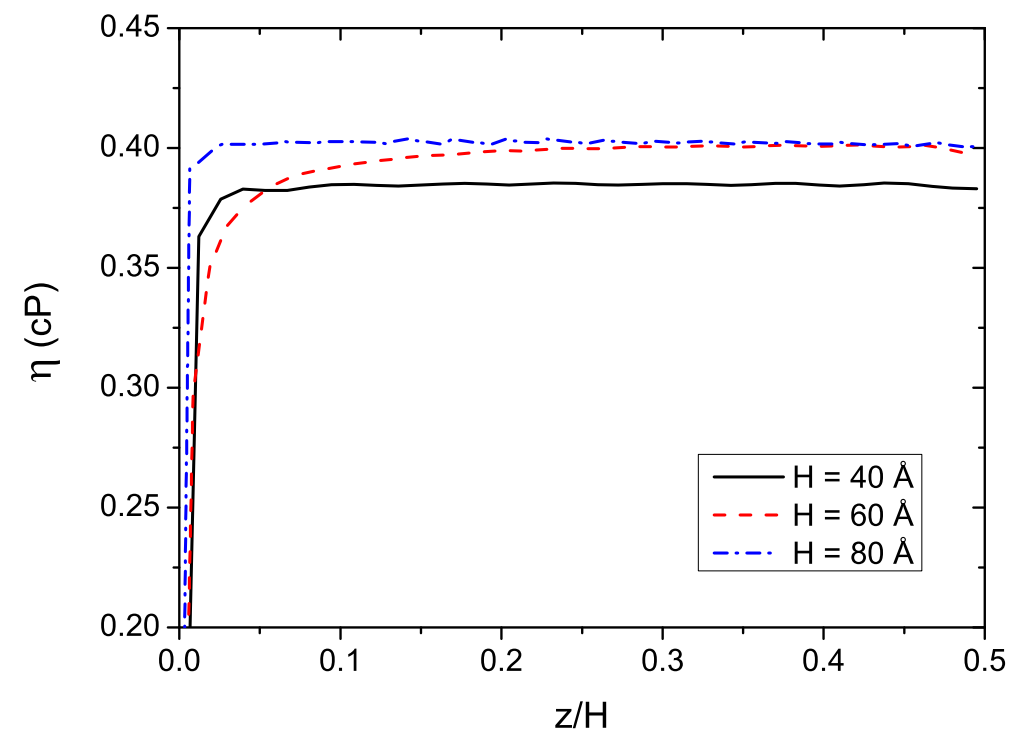

Fig. 14 Viscosity profiles in different pores at $310 \mathrm{~K}$. 
where $L_{s}$ is the slip length, $u_{x}$ the fluid velocity parallel to the $x$-direction, $u_{x}^{s}$ and $\left(\frac{\partial u_{x}}{\partial z}\right)_{s}$ are the fluid velocity at the HAP surface and its normal derivative at the HAP surface, respectively. These two values could be determined from the parabolic fit of the simulated velocity profile. Thus, a key point in the determination of the slip length is to properly situate the position interface. Here we used the density jump that can be observed when crossing the calcium-water interface to properly define this position. Finally, by considering the different parabolic profiles obtained for various pore widths, we obtain an average value of the slip length $L_{s} \equiv 1.88 \AA$. To the best of our knowledge, there is no published experimental or numerical determination of the slip length of water on hydroxyapatite surfaces. Note that for other mineral-water systems (sodium montmorillonite and SPC/E model of water), the typical slip length ranges from 2 to $6 \AA$. Furthermore, using the relation between the contact angle and the slip length as proposed by Sendner et al. [81], it could be possible to connect our slip length with wettability measurements of water on HAP substrates. Thus, according to the range of contact angles of water on hydroxyapatite ceramics made of natural bone measured by Joschek et al. [82] $\left(44.6^{\circ} \pm 15.4^{\circ}\right)$, the slip length should be in the range of $1.8-2.8 \AA$. Our simulated result falls into this range and provide therefore the first estimate of the value of the slip length of water on HAP.

Our simulated result falls into this range and therefore provides the first estimate of the slip length of water on HAP. For a macroscopic flow, the ideal boundary condition given by a 'no-slip' condition, i.e., the zero fluid velocity relative to the solid at the fluid-solid interface, has been very successful used in many situations. For a nanoscopic flow, the Navier model and slip length coefficient are usually used to account for the non-ideal boundary conditions at the wall. So, the slip length coefficient can be interpreted as a measure of the non-ideal boundary conditions at the wall. This coefficient is an interface property that depends on the fluid-solid interaction, which is accurately described by the interatomic potential method used in the present work, and its calculation should not be impacted by the shear viscosity of the fluid. In fact, the Navier boundary condition shows that the slip length coefficient is given by the ratio of the fluid velocity at the HAP surface and its normal derivative at the HAP surface (see Eq. (11)), and this ratio should be independent on the shear viscosity. Consequently, the underestimation of the shear viscosity should not affect the accuracy in the evaluation of the slip length of water on the surface of HAP. 


\section{Conclusion}

In this paper we have simulated liquid water confined between hydroxy-apatite nanopores using atomistic molecular dynamics simulations with a polarizable core-shell model to describe the HAP-water system. From these MD simulations several structural and dynamical properties of the water confined in HAP nanopores were computed as a function of the temperature and the size of the pore. The results obtained from simulations were coherent with those reported experimentally. In particular, we demonstrated that the diffusion of water in nanoscale pores of HAP is drastically reduced compared with bulk water because of specific molecular-level interactions occurring at the surface between the molecules of the solvent and the calcium and phosphate ions. We also have reported the first estimate of the value of the slip length of water on the surface of hydroxy-apatite, which is $1.88 \AA$.

The results obtained from this work are important to obtain a better understanding of how molecular level interactions control fluid flow within the bone as it has been suggested that liquid water may exist in pores of HAP of just a few nanometers. This is the point of a parent paper dealing with bone fluid flow [83]. In fact, such pores may exist in bone and neglecting the nanoscopic origin of fluid motion within the bone volume may result in large errors on the overall description of the fluid flow within the bone volume.

\section{Acknowledgements}

N.H. de Leeuw is grateful to 'Université Paris-Est Créteil' (UPEC) for financial support received during the course of this research. T.T. Pham is grateful to the 'Institut des sciences de l'ingénierie et des systèmes' (INSIS) of the 'Centre national de la recherche scientifique' (CNRS) for financial support received during the course of this research. D. Di Tommaso would like to thank the Royal Society, UK for the award of a Royal Society Industry Fellowship.

\section{Conflict of interest}

The authors declare that they have no conflict of interest. 


\section{References}

1. T.S.B. Narasaraju, D.E. Phebe, Journal of Materials Science 31(1), 1 (1996)

2. P. Fratzl, H.S. Gupta, E.P. Paschalis, P. Roschger, Journal of Materials Chemistry 14(14), 2115 (2004)

3. S.M. Kenny, M. Buggy, Journal of Materials Science: Materials in Medicine 14(11), 923 (2003)

4. C. Oddou, T. Lemaire, J. Pierre, B. David, in Porous media: applications in biological systems and biotechnology, ed. by K. Vafai (CRC Press, 2011), pp. 75-119

5. R.A. Robinson, S.R. Elliott, The Journal of Bone \& Joint Surgery 39(1), 167 (1957). URL + http://dx.doi.org/

6. P.A. Timmins, J.C. Wall, Calcified Tissue Research 23(1), 1 (1977). DOI 10.1007/BF02012759. http://dx.doi.org/10.1007/BF02012759

7. M.L. Knothe Tate, Journal of biomechanics 36(10), 1409 (2003)

8. S.C. Cowin, G. Gailani, M. Benalla, Philos. T. R. Soc. A 367, 3401 (2009)

9. E. Rohan, S. Naili, R. Cimrman, T. Lemaire, Journal of the Mechanics and Physics of Solids 60(5), 857 (2012)

10. T. Lemaire, E. Capiez-Lernout, J. Kaiser, S. Naili, E. Rohan, V. Sansalone, Bull. Math. Biol. 73, 2649 (2011)

11. E. Rohan, S. Naili, R. Cimrman, T. Lemaire, Comptes Rendus Mecanique 340(10), 688 (2012)

12. K. Norrish, Disc Faraday Soc 18, 120 (1954)

13. G. Karniadakis, A. Beskok, N.R. Aluru, Microflows and nanoflows: fundamentals and simulation, vol. 29 (Springer, 2006)

14. W. Stephen, T. Wolfie, FEBS Letters 206(2), 262 (1986). DOI http://dx.doi.org/10.1016/0014-5793(86)80993-0. URL http://www.sciencedirect.com/science/article/pii/0014579386809930

15. K. Sudarsanan, R.A. Young, Acta Crystallographica Section B 25(8), 1534 (1969). DOI 10.1107/S0567740869004298. URL http://dx.doi.org/10.1107/S0567740869004298

16. N.H. de Leeuw, S.C. Parker, Phys. Rev. B 58, 13901 (1998). DOI 10.1103/PhysRevB.58.13901. http://link.aps.org/doi/10.1103/PhysRevB.58.13901

17. N.H. de Leeuw, Phys. Chem. Chem. Phys. 6, 1860 (2004). DOI 10.1039/B313242K. URL http://dx.doi.org/10.1039/B313242K

18. B.G. Dick, A.W. Overhauser, Phys. Rev. 112, $90 \quad$ (1958). $\quad$ DOI 10.1103/PhysRev.112.90. http://link.aps.org/doi/10.1103/PhysRev.112.90

19. J.R. Errington, P.G. Debenedetti, Nature 409, 318 (2001)

20. U. Essmann, L. Perera, M.L. Berkowitz, T. Darden, H. Lee, L.G. Pedersen, The Journal of Chemical Physics 103(19), 8577 (1995). DOI http://dx.doi.org/10.1063/1.470117. URL http://scitation.aip.org/content/aip/journal/jcp/103/19/10.1063/1.470117

21. I.T. Todorov, W. Smithand, K. Trachenko, M.T. Dove, J. Mater. Chem. 16, 1911 (2006). DOI 10.1039/B517931A. URL http://dx.doi.org/10.1039/B517931A

22. S. Nosé, The Journal of Chemical Physics 81(1), 511 (1984). DOI http://dx.doi.org/10.1063/1.447334. URL http://scitation.aip.org/content/aip/journal/jcp/81/1/10.1063/1.447334

23. M. Wolthers, D. Di Tommaso, Z. Du, N.H. de Leeuw, Phys. Chem. Chem. Phys. 14, 15145 (2012). DOI 10.1039/C2CP42290E. URL http://dx.doi.org/10.1039/C2CP42290E 
24. S. Ruiz-Hernandez, N. Grau-Crespo, R.; Almora-Barrios, M. Wolthers, A.R. Ruiz-Salvador, N. Fernandez, N.H. de Leeuw, Chem. Eur. J. 18, 9828 (2012)

25. N.H. de Leeuw, S.C. Parker, Phys. Chem. Chem. Phys. 3, 3217 (2001)

26. I. Bako, J. Hutter, G. Palinkas, The Journal of Chemical Physics 117(21), 9838 (2002). DOI http://dx.doi.org/10.1063/1.1517039. URL http://scitation.aip.org/content/aip/journal/jcp/117/21/10.1063/1.1517039

27. J.A. Odutola, T.R. Dyke, The Journal of Chemical Physics 72(9), 5062 (1980). DOI http://dx.doi.org/10.1063/1.439795. URL http://scitation.aip.org/content/aip/journal/jcp/72/9/10.1063/1.439795

28. A. Chandra, Phys. Rev. Lett. 85, 768 (2000). DOI 10.1103/PhysRevLett.85.768. URL http://ink.aps.org/doi/10.1103/PhysRevLett.85.768

29. K. Wright, R.T. Cygan, B. Slater, Phys. Chem. Chem. Phys. 3, 839 (2001). DOI 10.1039/B006130L. URL http://dx.doi.org/10.1039/B006130L

30. S. Kerisit, S.C. Parker, J.H. Harding, The Journal of Physical Chemistry B 107(31), 7676 (2003). DOI 10.1021/jp034201b. URL http://dx.doi.org/10.1021/jp034201b

31. S. Kerisit, S.C. Parker, Journal of the American Chemical Society 126(32), 10152 (2004). DOI 10.1021/ja0487776. URL http://dx.doi.org/10.1021/ja0487776. PMID: 15303891

32. D.J. Cooke, J.A. Elliott, The Journal of Chemical Physics 127(10), 104706 (2007). DOI http://dx.doi.org/10.1063/1.2756840. URL http://scitation.aip.org/content/aip/journal/jcp/127/10/10.1063/1.2756840

33. T. Perry IV, R.T. Cygan, R. Mitchell, Geochimica et Cosmochimica Acta 71(24), 5876 (2007). http://dx.doi.org/10.1016/j.gca.2007.08.030. URL http://www.sciencedirect.com/science/article/pii/S0016703707005182

34. P. Raiteri, J.D. Gale, D. Quigley, P.M. Rodger, The Journal of Physical Chemistry C 114(13), 5997 (2010). DOI 10.1021/jp910977a. URL http://dx.doi.org/10.1021/jp910977a

35. J.D. Gale, P. Raiteri, A.C.T. van Duin, Phys. Chem. Chem. Phys. 13, 16666 (2011). DOI 10.1039/C1CP21034C. URL http://dx.doi.org/10.1039/C1CP21034C

36. A. Villegas-Jimenez, A. Mucci, M.A. Whitehead, Langmuir 25(12), 6813 (2009). DOI 10.1021/la803652x. URL http://dx.doi.org/10.1021/la803652x. PMID: 19405483

37. J.S. Lardge, D.M. Duffy, M.J. Gillan, M. Watkins, The Journal of Physical Chemistry C 114(6), 2664 (2010). DOI 10.1021/jp909593p. URL http://dx.doi.org/10.1021/jp909593p

38. F. Heberling, T.P. Trainor, J. Lützenkirchen, P. Eng, M.A. Denecke, D. Bosbach, Journal of Colloid and Interface Science 354(2), 843 (2011). DOI http://dx.doi.org/10.1016/j.jcis.2010.10.047. URL http://www.sciencedirect.com/science/article/pii/S0021979710012336

39. T. Hiemstra, P. Venema, W.H. Van Riemsdijk, Journal of Colloid and Interface Science 184(2), 680 (1996). DOI http://dx.doi.org/10.1006/jcis.1996.0666. URL http://www.sciencedirect.com/science/article/pii/S0021979796906669

40. P. Fenter, P. Geissbühler, E. Dimasi, G. Srajer, L.B. Sorensen, N.C. Sturchio, Geochimica et Cosmochimica Acta 64(7), 1221 (2000). DOI http://dx.doi.org/10.1016/S0016-7037(99)00403-2. URL http://www.sciencedirect.com/science/article/pii/S0016703799004032

41. F. Bruneval, D. Donadio, M. Parrinello, The Journal of Physical Chemistry B 111(42), 12219 (2007). DOI 10.1021/jp0728306. URL http://dx.doi.org/10.1021/jp0728306. PMID: 17915911

42. C.L. Freeman, J.H. Harding, D.J. Cooke, J.A. Elliott, J.S. Lardge, D.M. Duffy, The Journal of Physical Chemistry C 111(32), 11943 (2007). DOI 10.1021/jp071887p. URL http://dx.doi.org/10.1021/jp071887p 
43. D.L. Beveridge, F.M. DiCapua, Annual Review of Biophysics and Biophysical Chemistry 18, 431 (1989)

44. David, Journal of Molecular Liquids tbc, tbc (2001)

45. T.S. Hofer, H.T. Tran, C.F. Schwenk, B.M. Rode, Journal of Computational Chemistry 90, 211 âĂŞ217 (2004)

46. N.H. Di Tommaso, D.; de Leeuw, Crystal Growth \& Design 10, 4292âĂŞ4302 (2010)

47. L.X. Dang, D.E. Smith, Journal of Chemical Physics 99, 4229 (1993)

48. H.J.C. Berendsen, J.R. Grigera, T.P. Straatsma, Journal of Physical Chemistry 91, 6269 (1987)

49. H. Pan, J. Tao, T. Wu, R. Tang, Frontiers of Chemistry in China 2(2), 156 (2007). DOI 10.1007/s11458-007-0032-6. URL http://dx.doi.org/10.1007/s11458-007-0032-6

50. P.H.L. Sit, N. Marzari, J. Chem. Phys. 122, 204510 (2005)

51. D. Arismendi-Arrieta, J.S. Medina, G.S. Fanourgakis, R. Prosmiti, G. Delgado-Barrio, Applied Radiation and Isotopes 83(Part $\quad$ B), 115 (2014). DOI http://dx.doi.org/10.1016/j.apradiso.2013.01.020. http://www.sciencedirect.com/science/article/pii/S0969804313000213

52. J.S. Medina, R. Prosmiti, P. Villarreal, G. Delgado-Barrio, G. Winter, B. Gonzalez, J.V. Aleman, C. Collado, Chemical Physics 388(1ÃćâĆňâĂIJ3), 9 (2011). DOI http://dx.doi.org/10.1016/j.chemphys.2011.07.001. $\quad$ URL http://www.sciencedirect.com/science/article/pii/S0301010411002813

53. A.K. Soper, M.G. Phillips, Chemical Physics 107(1), 47 (1986). DOI http://dx.doi.org/10.1016/0301-0104(86)85058-3. URL http://www.sciencedirect.com/science/article/pii/0301010486850583

54. D. Di Tommaso, N.H. de Leeuw, The Journal of Physical Chemistry B 112(23), 6965 (2008). DOI 10.1021/jp801070b. URL http://pubs.acs.org/doi/abs/10.1021/jp801070b

55. E. Tang, D. Di Tommaso, N.H. de Leeuw, The Journal of Chemical Physics 130(23), 234502 (2009). DOI http://dx.doi.org/10.1063/1.3143952. URL http://scitation.aip.org/content/aip/journal/jcp/130/23/10.1063/1.3143952

56. A. Einstein, Investigations on the Theory of the Brownian Movement (Dover, New York, 1956)

57. B. Dünweg, K. Kremer, The Journal of Chemical Physics 99(9), 6983 (1993). DOI http://dx.doi.org/10.1063/1.465445. URL http://scitation.aip.org/content/aip/journal/jcp/99/9/10.1063/1.465445

58. I.C. Yeh, G. Hummer, The Journal of Physical Chemistry B 108(40), 15873 (2004). DOI 10.1021/jp0477147. URL http://pubs.acs.org/doi/abs/10.1021/jp0477147

59. B.D. Todd, D.J. Evans, P.J. Daivis, Phys. Rev. E 52, 1627 (1995). DOI 10.1103/PhysRevE.52.1627. URL http://link.aps.org/doi/10.1103/PhysRevE.52.1627

60. A. Botan, B. Rotenberg, V. Marry, P. Turq, B. Noetinger, The Journal of Physical Chemistry C 115(32), 16109 (2011). DOI 10.1021/jp204772c. URL http://pubs.acs.org/doi/abs/10.1021/jp204772c

61. J. Kestin, M. Sokolov, W.A. Wakeham, Journal of Physical and Chemical Reference Data 7(3), 941 (1978). DOI http://dx.doi.org/10.1063/1.555581. URL http://scitation.aip.org/content/aip/journal/jpcrd/7/3/10.1063/1.555581

62. R.B. Bird, E.S. Warren, N.L. Edwin, Transport Phenomena, revised 2nd edition edn. (John Wiley \& Sons, 2007)

63. A.P. Markesteijn, R. Hartkamp, S. Luding, J. Westerweel, The Journal of Chemical Physics 136(13), 134104 (2012). DOI http://dx.doi.org/10.1063/1.3697977. URL http://scitation.aip.org/content/aip/journal/jcp/136/13/10.1063/1.3697977 
64. G.S. Fanourgakis, J.S. Medina, P. R., J. Phys. Chem. A 116, 2564âĂŞ2570 (2012)

65. G. Guevara-Carrion, J. Vrabec, H. Hasse, The Journal of Chemical Physics 134(7), 074508 (2011). DOI http://dx.doi.org/10.1063/1.3515262. URL http://scitation.aip.org/content/aip/journal/jcp/134/7/10.1063/1.3515262

66. M.A. Gonzalez, J.L.F. Abascal, The Journal of Chemical Physics 132(9), 096101 (2010). DOI http://dx.doi.org/10.1063/1.3330544. URL http://scitation.aip.org/content/aip/journal/jcp/132/9/10.1063/1.3330544

67. G.S. Fanourgakis, J.S. Medina, R. Prosmiti, The Journal of Physical Chemistry A 116(10), 2564 (2012). DOI 10.1021/jp211952y. URL http://pubs.acs.org/doi/abs/10.1021/jp211952y

68. E.J.W. Wensink, A.C. Hoffmann, P.J. van Maaren, D. van der Spoel, The Journal of Chemical Physics 119(14), 7308 (2003). DOI http://dx.doi.org/10.1063/1.1607918. URL http://scitation.aip.org/content/aip/journal/jcp/119/14/10.1063/1.1607918

69. D. Bertolini, A. Tani, Phys. Rev. E 52, 1699 (1995). DOI 10.1103/PhysRevE.52.1699. http://link.aps.org/doi/10.1103/PhysRevE.52.1699

70. Y. Wu, H.L. Tepper, G.A. Voth, The Journal of Chemical Physics 124(2), 024503 (2006). DOI http://dx.doi.org/10.1063/1.2136877. URL http://scitation.aip.org/content/aip/journal/jcp/124/2/10.1063/1.2136877

71. J.T. Slusher, Molecular Physics 98(5), $287 \quad$ (2000). DOI 10.1080/00268970009483292. http://dx.doi.org/10.1080/00268970009483292

72. W.L. Jorgensen, The Journal of Physical Chemistry 90(7), 1276 (1986). DOI 10.1021/j100398a015. URL http://pubs.acs.org/doi/abs/10.1021/j100398a015

73. A. Glattli, X. Daura, W.F. van Gunsteren, The Journal of Chemical Physics 116(22), 9811 (2002). DOI http://dx.doi.org/10.1063/1.1476316. URL http://scitation.aip.org/content/aip/journal/jcp/116/22/10.1063/1.1476316

74. B. Hess, The Journal of Chemical Physics 116(1), 209 (2002). DOI http://dx.doi.org/10.1063/1.1421362. URL http://scitation.aip.org/content/aip/journal/jcp/116/1/10.1063/1.1421362

75. S. Balasubramanian, C.J. Mundy, M.L. Klein, The Journal of Chemical Physics 105(24), 11190 (1996). DOI http://dx.doi.org/10.1063/1.472918. URL http://scitation.aip.org/content/aip/journal/jcp/105/24/10.1063/1.472918

76. G.J. Guo, Y.G. Zhang, Molecular Physics 99(4), 283 (2001). $\quad$ DOI 10.1080/00268970010011762. http://dx.doi.org/10.1080/00268970010011762

77. P.E. Smith, W.F. van Gunsteren, Chemical Physics Letters 215(4), 315 (1993). DOI http://dx.doi.org/10.1016/0009-2614(93)85720-9. URL http://www.sciencedirect.com/science/article/pii/0009261493857209

78. K.R. Harris, L.A. Woolf, Journal of Chemical \& Engineering Data 49(4), 1064 (2004). DOI 10.1021/je049918m. URL http://pubs.acs.org/doi/abs/10.1021/je049918m

79. J.S. Ellis, M. Thompson, Phys. Chem. Chem. Phys. 6, 4928 (2004)

80. L. Bocquet, E. Charlaix, Chem. Soc. Rev. 39, 1073 (2010)

81. C. Sendner, D. Horinek, L. Bocquet, R.R. Netz, Langmuir 25(18), 10768 (2009)

82. S. Joschek, B. Nies, R. Krotz, A. Gopferich, Biomaterials 21(16), 1645 (2000)

83. T. Lemaire, T. Pham, E. Capiez-Lernout, N. de Leeuw, S. Naili, Journal of Biomechanics submitted, (2015) 